\title{
Halogenation processes of secondary organic aerosol and implications on halogen release mechanisms
}

\author{
J. Ofner ${ }^{1}$, N. Balzer ${ }^{1}$, J. Buxmann ${ }^{2}$, H. Grothe ${ }^{3}$, Ph. Schmitt-Kopplin ${ }^{4}$, U. Platt ${ }^{2}$, and C. Zetzsch ${ }^{1}$ \\ ${ }^{1}$ Atmospheric Chemistry Research Laboratory, University of Bayreuth, Germany \\ ${ }^{2}$ Institute for Environmental Physics, University of Heidelberg, Germany \\ ${ }^{3}$ Institute of Materials Chemistry, Vienna University of Technology, Austria \\ ${ }^{4}$ Research Unit Analytical Biogeochemistry, Helmholtz Zentrum Munich and Chair of Analytical Food Chemistry, \\ TUM, Freising/Weihenstephan, Germany
}

Correspondence to: J. Ofner (johannes.ofner@uni-bayreuth.de)

Received: 1 December 2011 - Published in Atmos. Chem. Phys. Discuss.: 27 January 2012

Revised: 6 June 2012 - Accepted: 7 June 2012 - Published: 4 July 2012

\begin{abstract}
Reactive halogen species (RHS), such as X·, $\mathrm{X}_{2}$ and HOX containing $\mathrm{X}=$ chlorine and/or bromine, are released by various sources like photo-activated sea-salt aerosol or from salt pans, and salt lakes. Despite many studies of RHS reactions, the potential of RHS reacting with secondary organic aerosol (SOA) and organic aerosol derived from biomass-burning (BBOA) has been neglected. Such reactions can constitute sources of gaseous organohalogen compounds or halogenated organic matter in the tropospheric boundary layer and can influence physicochemical properties of atmospheric aerosols.

Model SOA from $\alpha$-pinene, catechol, and guaiacol was used to study heterogeneous interactions with RHS. Particles were exposed to molecular chlorine and bromine in an aerosol smog-chamber in the presence of UV/VIS irradiation and to RHS, released from simulated natural halogen sources like salt pans. Subsequently, the aerosol was characterized in detail using a variety of physicochemical and spectroscopic methods. Fundamental features were correlated with heterogeneous halogenation, which results in new functional groups (FTIR spectroscopy), changes UV/VIS absorption, chemical composition (ultrahigh resolution mass spectroscopy (ICR-FT/MS)), or aerosol size distribution. However, the halogen release mechanisms were also found to be affected by the presence of organic aerosol. Those interaction processes, changing chemical and physical properties of the aerosol are likely to influence e.g. the ability of the aerosol to act as cloud condensation nuclei, its potential to adsorb other gases with low-volatility, or its contribution to radiative forcing and ultimately the Earth's radiation balance.
\end{abstract}

\section{Introduction}

Besides their importance for stratospheric ozone depletion, reactive halogen species (RHS) also play an important role during tropospheric ozone destruction (e.g. Jobson et al., 1994; Barrie and Platt, 1997; Foster et al., 2001). These effects were indicated by smog-chamber experiments of halogen release from $\mathrm{NaCl}$ (e.g. Zetzsch et al., 1988; Behnke and Zetzsch, 1990). Various atmospheric halogen species were monitored within the tropospheric boundary layer (e.g. Platt, 2000), using Differential Optical Absorption Spectroscopy (DOAS: Platt and Stutz, 2008). Apart from anthropogenic organohalogen sources, several natural sources for halogens and organohalogen in the troposphere and the boundarylayer were investigated. Wagner et al. (2007) measured enhanced tropospheric $\mathrm{BrO}$ in situ over the coast of Antarctica using multi-axis DOAS. Enami et al. (2007) report an iodine catalysed oxidation of bromide and chloride to molecular halogen species in the troposphere. Important sources for those RHS are the halogen-release from sea-salt aerosol (e.g. Finlayson-Pitts, 2003) and the heterogeneous reactions on those aerosol surfaces (Rossi, 2003). Frinak and Abbatt (2006) report $\mathrm{Br}_{2}$ production from heterogeneous reaction of gas-phase $\mathrm{OH}$ with aqueous salt solutions. The formation of $\mathrm{Cl}_{2}$ by oxidation of $\mathrm{Cl}^{-}$in the presence of inorganic aerosols and a strong contribution to the overall chlorine tropospheric budget has been suggested by Zetzsch and Behnke (1993). The tropospheric reaction mechanisms of halogens significantly differ from the stratospheric ones (Platt and Hönninger, 2003). The heterogeneous release of 
RHS from sea-salt aerosol or salt pans is based on the so called "bromine explosion" effect (Platt and Janssen, 1996). Von Glasow and Crutzen (2004) summarized the complex reaction mechanisms of halogen release from various sources, supported by model calculations. Modelling of measurements of tropospheric halogen chemistry above the Dead Sea (Tas et al., 2006) allowed a detailed view on complex reaction mechanisms. Interestingly, these halogen-release mechanisms seem to play a major role also in polar boundary-layer ozone depletion events (Simpson et al., 2007). Recent smog chamber studies exhibit halogen release from simulated salt pans with a wet $\mathrm{NaCl} / \mathrm{NaBr}$ surface (Buxmann et al., 2012). Those release mechanisms seem to be very similar to the well-investigated ones of sea-salt aerosol.

While sources of reactive halogen species in the troposphere are relatively well studied, sinks are hardly known. A possible sink is the reaction with organic matter, which is well known from water disinfection (e.g. Gallard and von Gunten, 2002; Uyguner et al., 2004). Voudrias et al. (1985) report the reaction of phenolic compounds like phenol, catechol, and guaiacol with free chlorine by drinking water treatment processes and the formation of chlorinated aromatic compounds.

Norwood et al. (1980) studied the chlorination of selected aromatic model substances of aquatic humic material and found the formation of chloroacetic acid. The formation of organochlorine compounds in the condensed phase from soil's humic acids, atmospheric humic-like substances (HULIS), and phenolic moieties were studied by Fahimi et al. (2003) and by Wentworth et al. (2011), suggesting a Fenton-type reaction mechanism. The natural abiotic formation of trihalomethanes (THM) in soil was characterized in detail by Huber et al. (2009). More than 40 reaction products, such as chlorinated ketones, carboxylic acids, ketoacids, lactones, and furanones, were identified from the chlorination of orcinol (3,5-dihydroxy-toluene) by Tretyakova et al. (1994). Ishikawa et al. (1986) studied the reaction of chlorine and bromine with humic substances and found a post-bromination of chlorinated compounds. Caregnato et al. (2007) used flash-photolysis experiments to study the reactions of chlorine radicals with humic acids and reported rate constants up to $(3 \pm 2) \times 10^{10} \mathrm{M}^{-1} \mathrm{~s}^{-1}$. They suggested that these high values could result from the interaction of $\mathrm{Cl}_{2}^{--}$with carboxylic acid functional groups of humic acids.

THM formation from the reaction of molecular chlorine with humic substances was measured by Uyguner et al. (2004) in water-treatment processes. Schöler and Thiemann (2005) report the natural formation of THM in the marine and terrestrial environment. Halogenated methanes formed by haloform-type reactions were observed by Carpenter et al. (2005). Boyce and Hornig (1983) report the reaction pathways of THM formation by halogenation of dihydroxy-aromatic compounds, acting as models for humic acids. The authors proposed an abiotic formation pathway via reaction of HOX with organic material on the quasi- liquid layer above the sea ice/snow pack. Kopetzky and Palm (2006) reported the formation of halogenated methanes and acetones by halogenation of humic acids in highly saline solutions. Bromoform, bromoacetones, and THM are reported after ozonization of saline solutions containing significant amounts of humic acids (Sörgel, 2007).

The formation of even simpler molecules like phosgene, chloroacetone and 1,1-dichloroacetone after interaction of hydrocarbons with halogens released from $\mathrm{NaCl}$ aerosol was found by Zetzsch and Behnke (1992) in aerosol smogchamber experiments. A detailed review on these formation pathways is given by Behnke and Zetzsch (2005). The importance of hydrophobic organics with phenolic acidity in producing high amounts of brominated organics was reported by Huang et al. (2004).

Smoydzin and von Glasow (2007) discussed the influence of organic surface films on halogen release from sea salt aerosols. Rudich (2003) expects a simultaneous occurrence of high concentrations of bromine and chlorine, released from marine aerosols, with organic aerosols in marine environments. Moise and Rudich (2001) used a low-pressure flow reactor to study the reactive uptake of $\mathrm{Cl}$ and $\mathrm{Br}$ by organic monolayers of alkanes and alkenes. FTIR spectroscopy allowed them monitoring an almost complete disappearance of aliphatic C-H bonds. Hydrogen abstraction and an enhancement of the hydrophilic character of the surfaces were reported (Rudich, 2003).

While the atmospheric chemistry community takes increasing interest in heterogeneous processing reactions of atmospheric aerosols, (e.g. George and Abbatt, 2010), only a few studies are focused on halogenated particulate matter or organic aerosols like secondary organic aerosol (SOA) or biomass burning organic aerosol (BBOA). Rahn et al. (1979) measured halogen-containing particles as anthropogenic pollutants in New York finding $\mathrm{Br}$ as the most important halogen. Halogenated aerosols were reported by Mosher et al. (1993) in Greenland and related to the photochemical aerosol production from biogenic organo-halogens. Cldominated particulate matter from anthropogenic sources, like pesticides, was measured by Xu et al. (2005) at a downtown site in Beijing. Holzinger et al. (2010) found halogenated compounds in organic aerosols at the Sonnblick observatory (Austria), but did not identify them. Basic work on SOA formation induced by chlorine atoms was done by Cai and Griffin (2006) and Cai et al. (2008), when they studied the processing and SOA formation yields of $\alpha$-pinene, $\beta$-pinene, limonene, and toluene. Karlsson et al. (2001) used a flash photolysis system and a continuous flow reactor to study the homogeneous nucleation of toluene by chlorine atoms in detail.

The present study investigates physicochemical changes of SOA and related precursors caused by RHS. Figure 1 indicates these interactions of RHS released from sea-salt aerosol or salt lakes with SOA, BBOA, or atmospheric HULIS and the formation of halogenated SOA/BBOA 


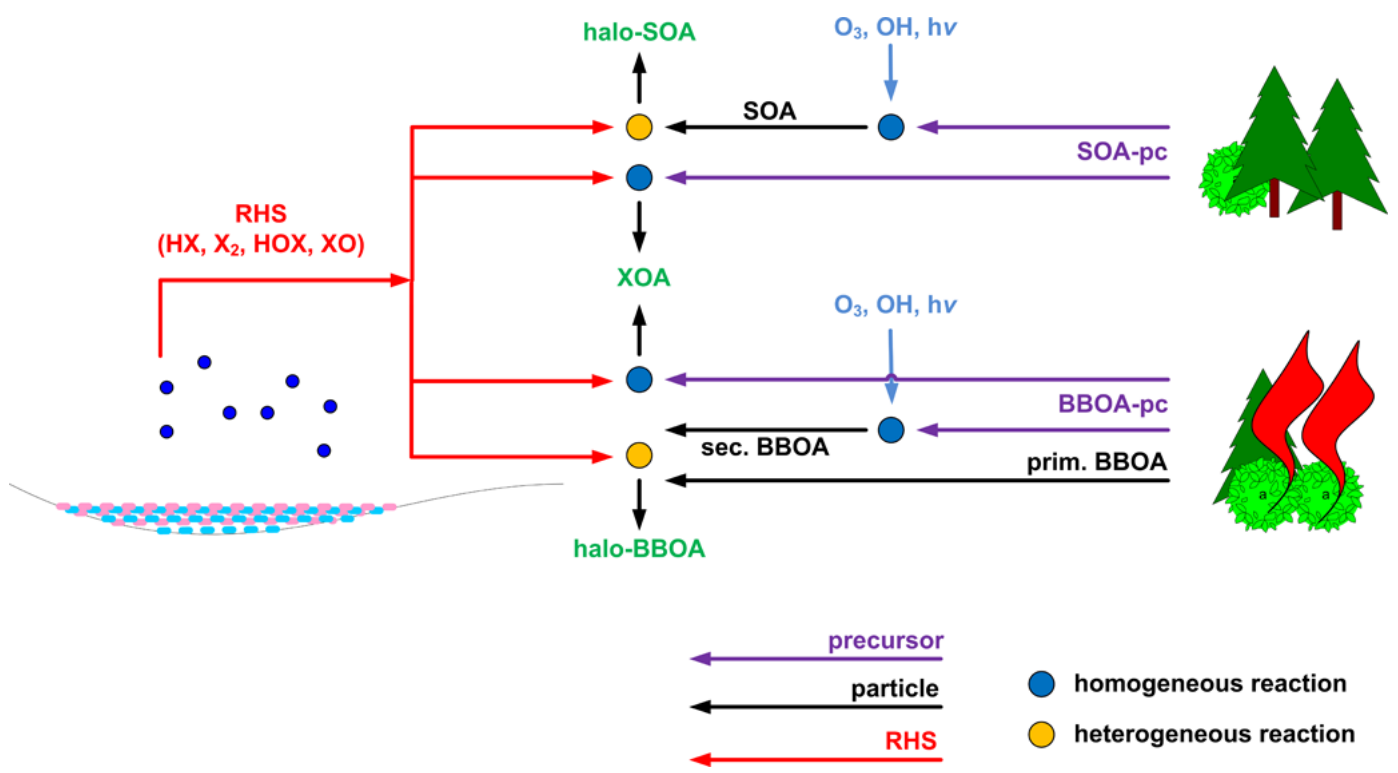

Fig. 1. Possible interactions of RHS released from sea-salt aerosol or salt lakes with SOA, BBOA and related gaseous precursors (SOApc, BBOA-pc), forming halogenated SOA/BBOA (halo-SOA/halo-BBOA) via heterogeneous reaction or halogen-induced organic aerosol (XOA) via homogeneous reaction.

(halo-SOA/halo-BBOA), halogen-induced SOA formation (XOA), or volatile organic or inorganic halogen species. All studies were based on aerosol smog-chamber experiments. The biogenic $\alpha$-pinene, catechol, and guaiacol were chosen for producing secondary organic aerosol in the smog chamber. The terpenoid $\alpha$-pinene is a well-known precursor for aliphatic SOA, investigated in several studies (e.g. Jonsson et al., 2007; Saathoff et al., 2009). Aerosol chamber studies have been performed on particle formation and processing from $\alpha$-pinene (e.g. Iinuma et al., 2004). The transformation pathways of this model substance are summarized by $\mathrm{Yu}$ et al. (2008). The formation of secondary organic aerosol from catechol and guaiacol by ozone was investigated by Coeur-Tourneur et al. (2009), Ofner et al. (2010) and (2011). The use of these aerosols as a model for the aromatic fraction of atmospheric HULIS has been discussed based on physicochemical studies. The halogen interaction of these model aerosols was studied by photolysis of molecular chlorine and bromine and with halogens released from seasalt aerosol or from a simulated salt pan. The term aerosol must in this case be used according to its exact definition: particles and their surrounding gas phase, which contains, in addition to the common atmospheric gas-phase species, also volatile oxidation products of the aerosol formation process. This is especially important for aerosol smog-chamber studies, where particles and gas phase can be separated from meteorological effects.

\section{Experimental setup and methods}

Three different types of experimental setups were used to study the processing of SOA by RHS:

1. Molecular halogen photochemical experiments were performed to study the transformation of SOA by photolyzed gaseous halogens under well-defined simulated conditions.

2. The model halogenations were compared to SOA halogenation processes by halogens released from a simulated salt pan.

3. Studying the interaction of SOA with RHS released from sea-salt aerosol, using the physicochemical methods described below, is hampered by a huge matrix contribution of the sea-salt aerosol. Hence, no data is presented for this part of the study. Details on those matrix effects and few results have been reported by Ofner (2011).

Racemic $\alpha$-pinene with a purity of $98 \%$ (Aldrich, 14752-4) was used for SOA formation from a terpene-type precursor. Physicochemical characterization of SOA from $\alpha$-pinene has been reported by Ofner (2011). SOA formation from catechol and guaiacol is described in detail by Ofner et al. (2010, 2011).

\subsection{Molecular halogen photochemical experiments}

Molecular halogen photochemical experiments were performed in a $700 \mathrm{~L}$ aerosol smog-chamber (Nolting et al., 
1988; Ofner, 2011; Ofner et al., 2011). A medium-pressure metal vapour lamp (Osram HMI, $4000 \mathrm{~W}$ ) was used as a solar simulator. Its spectrum is cut off by a water cooled glass plate at $292 \mathrm{~nm}$ to avoid photolysis by the UV-C component of the lamp spectrum and to generate a spectrum similar to the solar spectrum. Bromine and chlorine atoms were generated by photolysis (solar simulator) of molecular bromine (Fluka, 196050, puriss., $>99.0 \%$ ) and molecular chlorine (Aldrich, 295132-454G, $>99.5 \%$ ). All organic aerosols were formed by gas-to-particle conversion in-situ in the aerosol smog-chamber at two different conditions, with simulated sunlight and ozone at $0 \%$ relative humidity and at $25 \%$ relative humidity. The relative humidity was monitored as described by Ofner et al. (2011). Ozone preparation and monitoring are also described in this previous publication. After one hour of aerosol formation, a stoichiometric amount (1 molecule of $\mathrm{X}_{2}$ to 1 molecule precursor) of molecular bromine or chlorine was added into the aerosol smog-chamber. A condensation-nucleus-counter (CNC) and a differential-mobility-particle-sizer (DMPS) were used for analysing the evolution of the aerosol size distribution. The experiments were performed with $300 \mathrm{ppb}$ aerosol precursor, $1 \mathrm{ppm}$ ozone and $300 \mathrm{ppb}$ of molecular halogens. Various methods were used to investigate spectroscopic features of the particles, the chemical transformation of functional groups and gaseous species as well as to determine halogenated substances within the particles: Long-path FTIR spectroscopy (LP-FTIR), attenuatedtotal-reflection FTIR (ATR-FTIR), UV/VIS spectroscopy using an integrating Ulbricht sphere, ultrahigh resolution mass spectroscopy (ion cyclotron - Fourier transform/mass spectroscopy (ICR-FT/MS)). All methods are described in detail by Ofner et al. (2011). To achieve an adequate amount of particulate matter for the methods mentioned above, $5 \mathrm{ppm}$ of the aerosol precursor, $20 \mathrm{ppm}$ of ozone and, after one hour of aerosol formation, $5 \mathrm{ppm}$ of molecular halogens were added.

\subsection{Photochemical activation salt-pan experiments}

The interaction of organic aerosols with halogens released from a simulated salt pan was studied using a $3500 \mathrm{~L}$ Teflon smog-chamber with a salt pan mounted in the chamber on a suspended Teflon sheet (Buxmann et al., 2012). The chamber was flushed with purified air (Ofner et al., 2011). Seven 1200 W HMI lamps, with a water-cooled glass plate as described above, are used to simulate the solar spectrum. A multi-reflection cell (White-cell) coupled with DOAS was used to observe $\mathrm{BrO}$ levels directly. The concentrations of $\mathrm{OH}$ and $\mathrm{Cl}$ radicals were quantified indirectly by monitoring the decay of several hydrocarbons using the radical clock method (Zetzsch and Behnke, 1992). For details on the experimental setup, the analytical methods used and results about RHS release from the salt pan in the absence of SOA, see Buxmann et al. (2012).
Particle formation was studied using the same CNCDMPS system as described above. ATR-FTIR spectroscopy, diffuse-reflectance UV/VIS spectroscopy, and ICR-FT/MS were used to characterize physicochemical changes of the processed SOA.

The salt-pan experiments were carried out at $60 \%$ relative humidity. SOA from catechol was formed in the dark for 30 min without activating the halogen-release mechanism. SOA from guaiacol could only be formed in the presence of simulated sunlight. $300 \mathrm{ppb}$ of the SOA precursors were used to generate the SOA particles. $1 \mathrm{ppm}$ of ozone was added to the smog chamber to start the SOA formation process (about $600 \mathrm{ppb}$ were consumed by the SOA formation process) and to initiate the release of RHS from the salt pan.

\section{Results of molecular reaction experiments}

Based on former smog chamber experiments regarding SOA formation, we have carried out a molecular reaction experiment to determine the influence of well-defined halogen species on the different types of organic aerosol. The complex reaction schemes of halogen activation and release from heterogeneous surfaces have not been reinvestigated in the present study. We focus on the heterogeneous reaction of well-defined model aerosols with molecular halogens photolyzed by the UV/VIS irradiation of the solar simulator, which gives access to the understanding of specific pathways of transformation with respect to the physicochemical properties.

\subsection{Change of aerosol size-distribution}

The aerosol size distributions of the organic model aerosols are strongly influenced by the interaction with halogens (Fig. 2). The addition of halogens causes an increase of the mean particle diameter, observed with nearly all studied aerosols. The observed increase is stronger during the photochemical transformation in the presence of chlorine than of bromine. While this behaviour holds for SOA from catechol, SOA from guaiacol and $\alpha$-pinene exhibits some special features.

The photochemical reaction of chlorine with SOA from guaiacol forms a second mode of the aerosol size distribution. Due to the fact that the methyl-ether-group is the only difference between the catechol and the guaiacol precursor, the formation of this second particle mode might be related to this structural difference. The formation of this mode appears to be caused by a strong supersaturation of the remaining gas-phase species of the oxidized organic precursor. Only low aerosol formation yields are observed during SOA formation from guaiacol with ozone (Ofner et al., 2011). Therefore, a significant amount of oxidized but still volatile gaseous organic species must be present. These species seem to be activated by the reaction with RHS (either by hydrogen 

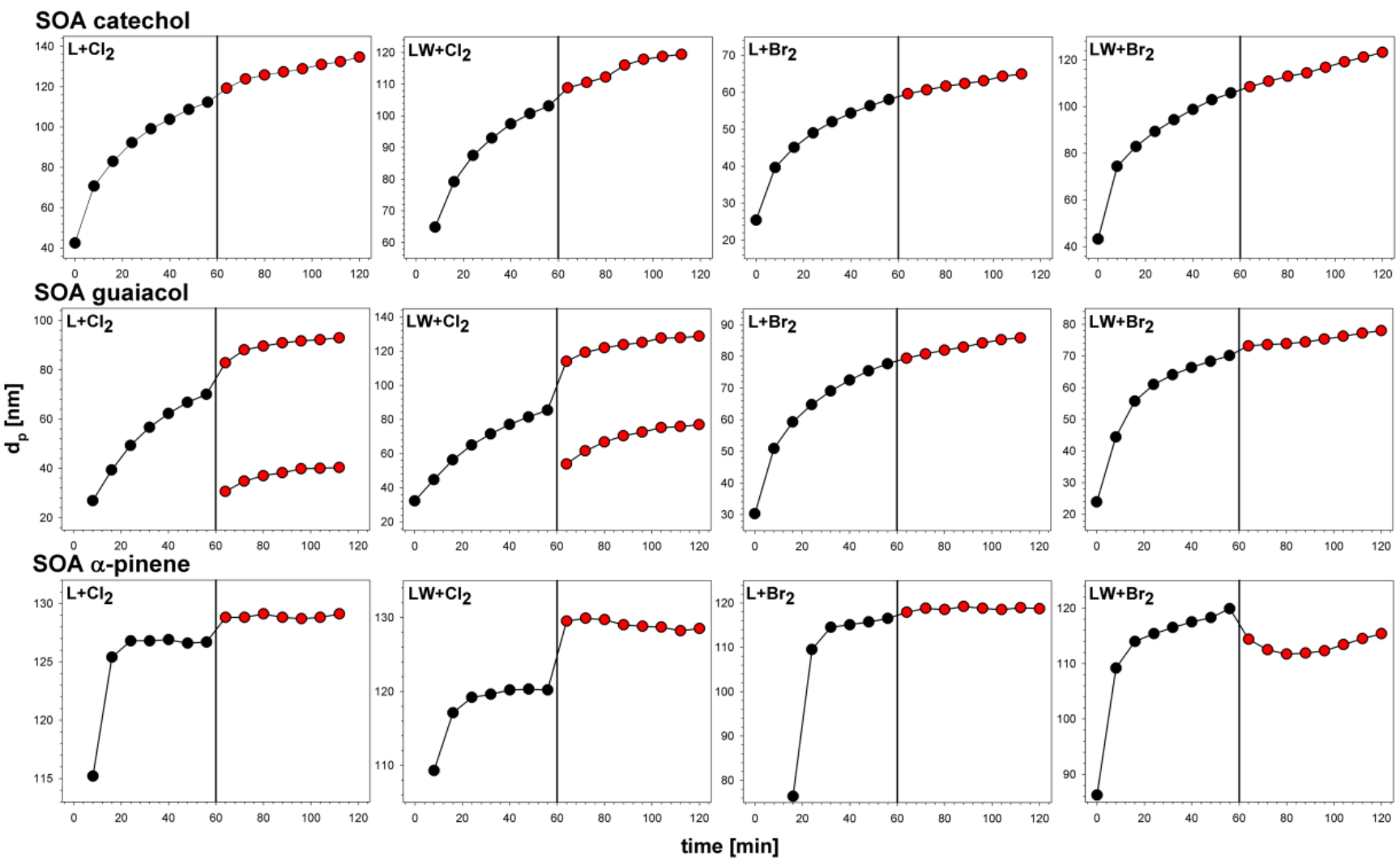

Fig. 2. Change of the mean particle diameter of organic aerosols by the reaction with gaseous halogen species for aerosol smog chamber experiments with photolyzed $\mathrm{Cl}_{2}$ and $\mathrm{Br}_{2}$, respectively (L: SOA formed with simulated sunlight at $0 \%$ relative humidity; LW: SOA formed with simulated sunlight at $25 \%$ relative humidity). The injection of the molecular halogen species is marked by the vertical lines at about 60 min after starting the irradiation and SOA formation.

abstraction from the methyl-ether group or by splitting of the ether bond), forming low-volatile compounds and leading to a strong supersaturation. This supersaturation seems to be strong enough to not only lead to growth of existing particles but also causes formation of new particles. This second mode is not observed during the photochemical reaction with bromine.

Although the mean particle diameter increases by the reaction of the organic aerosol from catechol and guaiacol with halogens, another effect appears during the reaction of $\alpha$ pinene SOA with the halogen species. The mean diameter increases immediately after adding the halogens, but it remains constant (at $0 \%$ relative humidity) or decreases slightly (at $25 \%$ relative humidity) afterwards. The decrease of the mean particle diameter is stronger during the photochemical reaction with bromine than with chlorine.

Hence, the evolution of the aerosol size distribution of different organic aerosol reacting photochemically with halogens is not only dependent on the reacting halogen (chlorine or bromine) and the relative humidity, but also on the chemical composition of the organic aerosol. The chemical structure of the organic precursor and therefore the structural and functional features of the resulting secondary or- ganic aerosols strongly influence the evolution of the mean particle diameter.

\subsection{Optical properties in the UV/VIS range}

The optical properties of SOA in the UV/VIS spectral range are strongly altered by the reaction with halogens (Fig. 3). The diffuse-reflectance UV/VIS spectra of organic aerosols from the aromatic precursors catechol and guaiacol, reported by Ofner et al. (2011), exhibit strong changes of the absorption peaks and band shapes. After the reaction with chlorine species, the reported main absorption regions at 222 and $275 \mathrm{~nm}$ shift down to 210 and $250 \mathrm{~nm}$, and the broad absorption extending up to $600 \mathrm{~nm}$ is reduced and limited up to $400-450 \mathrm{~nm}$. The effect of bromine on the diffuse-reflectance UV/VIS spectrum is completely different. While the main absorption of unprocessed SOA and SOA reacted with chlorine species is at 220 or $210 \mathrm{~nm}$, SOA reacted with bromine species exhibits the maximum absorption between 300 and $350 \mathrm{~nm}$, and the absorption of the visible spectrum is significantly enhanced up to the red end.

SOA from $\alpha$-pinene does not exhibit these strong effects. Only small changes of the diffuse-reflectance UV/VIS spectrum are caused by the reaction with halogens. The 

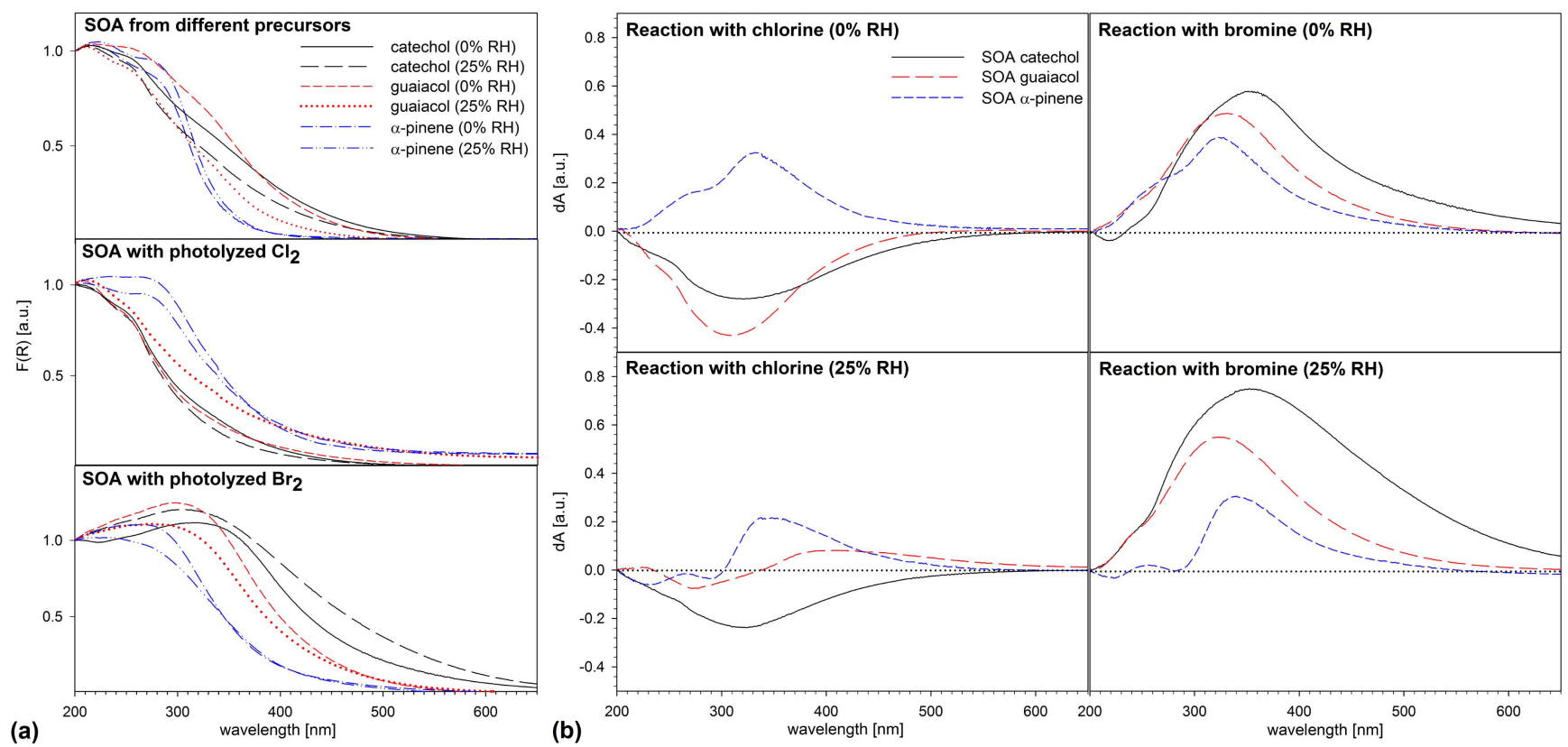

Fig. 3. Single absorption spectra $F(R)$ (a) and change of the differential absorbance (dA) (b) in the UV/VIS spectra region due to the reaction of SOA with RHS formed from photolysis of molecular chlorine or bromine.

absorption up to higher wavelengths is slightly enhanced after reaction with bromine. For all halogen reactions, the maximum of absorption is located at $275 \mathrm{~nm}$, while the maximum of the unprocessed SOA from $\alpha$-pinene is at $225 \mathrm{~nm}$.

A full quantification of the diffuse-reflectance UV/VIS spectra $F(R)$ was not possible, according to limitations (Kortüm and Oelkrug, 1966): the required thickness of the aerosol sample on the filters could not be achieved, limited by the particle density and weight, as well as by the aerosol smog-chamber volume. Therefore, calculation of a differential absorbance (dA) was employed in the UV/VIS range to demonstrate the optical changes caused by the different halogen species. The single absorption spectra were normalized at $200 \mathrm{~nm}$ to an absorbance of 1, using the normalization coefficients $\lambda$, which changed the original absorption at $200 \mathrm{~nm}$ by about $5 \%$. dA was calculated according to Eq. (1), where $\lambda^{*} \cdot F(R)^{*}$ is the normalized absorption spectrum of the aerosol after the reaction with RHS and $\lambda \cdot F(R)$ is the normalized absorption spectrum of the aerosol before the reaction.

$\mathrm{dA}=\lambda^{*} \cdot F(R)^{*}-\lambda \cdot F(R)=-\lg \frac{I^{*}}{I_{0}}+\lg \frac{I}{I_{0}}=\lg \frac{I}{I^{*}}$

The differential absorbance spectra clearly indicate changes of the optical properties of the organic aerosols according to the electronic spectrum caused by the heterogeneous reaction of SOA with RHS (Fig. 3). The aerosols from the aromatic precursors exhibit a negative dA at about $300 \mathrm{~nm}$ for the photochemical reaction with chlorine, which can be related to a bleaching of the aerosol. The highest maximum of absorption is shifted to the blue end of the diffuse-reflectance
UV/VIS spectrum. The more aliphatic SOA from $\alpha$-pinene does not exhibit this behavior. Some absorbing compounds are formed by the photochemical reaction with chlorine up to $350 \mathrm{~nm}$. The photochemical reaction with bromine shifts the absorption of all three aerosols to the red end of the spectrum. This behavior is strongest for the aromatic SOA from catechol and weakest for the aliphatic SOA from $\alpha$-pinene. The shift to the red end of the spectrum is also visible on the filter samples. SOA processed with bromine exhibit a redbrown golden color.

UV/VIS absorption of aerosols from aromatic precursors is more strongly influenced by halogens than the absorption of aliphatic aerosol from $\alpha$-pinene. However, the interaction of SOA with RHS significantly changes the absorption properties and the interaction with solar radiation.

\subsection{Changes of vibrational features of gaseous species and particulate matter}

During the reaction of RHS with the SOA, several changes of gaseous species occur, which were identified by longpath absorption FTIR spectroscopy (Fig. 4). After injecting the halogens, a strong increase of $\mathrm{CO}_{2}$ is monitored (2349 and $668 \mathrm{~cm}^{-1}$ ). At the same time, ozone, which was not totally consumed by the aerosol formation process, decreases $\left(1044 \mathrm{~cm}^{-1}\right)$. Furthermore, the $\mathrm{H}-\mathrm{X}$ species are formed. Gaseous $\mathrm{HCl}$, represented by the $v(\mathrm{H}-\mathrm{Cl})$ at $2887 \mathrm{~cm}^{-1}$, is formed at higher yields than $\mathrm{HBr}\left(2559 \mathrm{~cm}^{-1}\right)$. While $\mathrm{CO}_{2}$ and $\mathrm{HX}$ are formed, the aromatic or aliphatic $v(\mathrm{C}-\mathrm{H})$ functionalities degrade. This is observed with all three model aerosols: SOA from catechol only exhibits the aromatic 


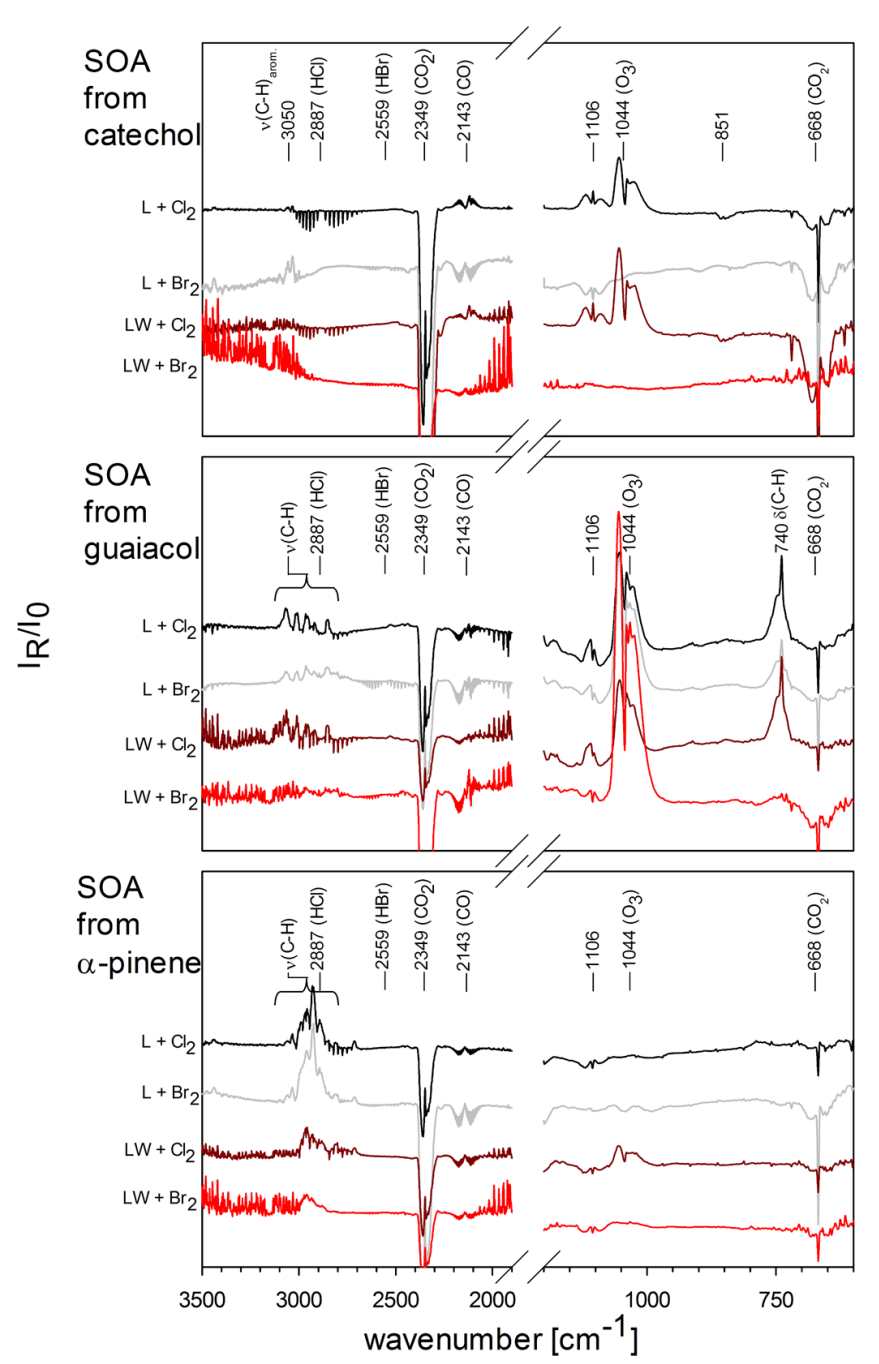

Fig. 4. Long-path absorption FTIR spectra of the heterogeneous reaction of SOA with RHS: L: SOA formed with simulated sunlight at $0 \%$ relative humidity; LW: SOA formed with simulated sunlight at $25 \%$ relative humidity. Due to the fact, that the represented spectra are transmission spectra, positive absorptions correspond to decreasing species, while negative absorptions indicate increasing species.

$v(\mathrm{C}-\mathrm{H})$ at $3050 \mathrm{~cm}^{-1}$, SOA from guaiacol the aromatic $v(\mathrm{C}-\mathrm{H})$ at $3050 \mathrm{~cm}^{-1}$ and the aliphatic methyl-ether $v(\mathrm{C}-\mathrm{H})$ between 2800 and $3000 \mathrm{~cm}^{-1}$. The aliphatic $v(\mathrm{C}-\mathrm{H})$ of the $-\mathrm{CH}_{3}$ groups of SOA from $\alpha$-pinene also degrades by the influence of halogens. The prominent $\delta(\mathrm{C}-\mathrm{H})_{\text {out-of-plane }} \mathrm{ab}-$ sorption at $740 \mathrm{~cm}^{-1}$ of SOA from guaiacol (Ofner et al., 2011) also decreases but remains unchanged for SOA from guaiacol processed with bromine at $25 \%$ relative humidity $\left(\mathrm{LW}+\mathrm{Br}_{2}\right)$. Furthermore, $\mathrm{CO}$ at $2143 \mathrm{~cm}^{-1}$ is formed during the reaction of all organic aerosols with RHS under various conditions. In case of the interaction of SOA derived from catechol, with RHS, CO is consumed by further reaction with chlorine at $0 \%$ and $25 \%$ relative hu- midity. Additionally, an absorption at $850 \mathrm{~cm}^{-1}$ increases. This absorption is structured as typical of gaseous species showing $\mathrm{P}$ - and R-branches and can be allocated as phosgene $\left(\mathrm{OCCl}_{2}\right)($ Siebert, 1966). The associated $v(\mathrm{C}=\mathrm{O})$ at $1827 \mathrm{~cm}^{-1}$ could not be identified because of the weakly structured carbonyl-stretching region. At $1106 \mathrm{~cm}^{-1}$, absorption of a gas-phase species with PQR-structured branches is visible in all long-path absorption spectra. The allocation of this vibration to a specific molecule is not clear. Formic acid could be a possible candidate with a very strong $v(\mathrm{C}$ O) at $1105 \mathrm{~cm}^{-1}$. The strong $\tau$ vibration at $638 \mathrm{~cm}^{-1}$ could be covered by $\mathrm{CO}_{2}$, and all other vibrations are weak or within the carbonyl-stretching region (Shimanouchi, 1972). All other gases were assigned by their reported group frequencies (Siebert, 1966). A detailed assignment of measured bands to functional groups is given in Table 1 .

To investigate the transformation of functional groups, ATR-FTIR spectroscopy (Ofner et al., 2009) of the particulate phase of the aerosol was performed on KRS5 crystals (Fig. 5). The infrared spectra of the condensed phase of the model aerosols were reported for $\alpha$-pinene (Sax et al., 2005) and for catechol and guaiacol (Ofner et al., 2011). After reacting with RHS, significant changes occur in the infrared spectra of the aerosols. While the $v(\mathrm{C}=\mathrm{O})$ absorption is the most prominent of the untreated aerosols, the vibration due to this functional group becomes less important. Especially the SOA from catechol processed with RHS exhibits two bands at 1372 and $1303 \mathrm{~cm}^{-1}$ as the strongest ones. These two bands can also be found in the treated SOAs from guaiacol and $\alpha$-pinene. According to the literature (Shevchenko, 1963; Baes and Bloom, 1989 and Ofner et al., 2011) these absorptions can be allocated to carboxylic acids, the carboxylate anion, and other $v(\mathrm{C}-\mathrm{O})$ vibrations of aromatic or aliphatic $\mathrm{C}-\mathrm{OH}, \mathrm{R}-\mathrm{COO}-\mathrm{R}$, or R-O-R. The missing dominance of the carbonyl stretch vibration, as observed in the present study, was reported by Rontu and Vaida (2008), studying perfluorocarboxylic acids. In their study the most prominent absorption between 1000 and $1400 \mathrm{~cm}^{-1}$ was $v(\mathrm{C}-\mathrm{F})$, but also $v(\mathrm{C}-$ $\mathrm{O})$ bands are more intense than the $v(\mathrm{C}=\mathrm{O})$ band. Hence, RHS seem to significantly influence carboxylic acids of SOA by degradation or changing their vibrational properties as $\alpha$ or $\beta$-substituent.

Absorptions between 700 and $800 \mathrm{~cm}^{-1}$ were reported for SOA from catechol and guaiacol (Ofner et al., 2011), when the SOA is formed under simulated sunlight at $25 \%$ relative humidity. For $\alpha$-pinene, the lowest observed absorption is located at $854 \mathrm{~cm}^{-1}$ (Sax et al., 2008). The ATR spectra of treated SOA from catechol exhibit a strong absorption between 800 and $700 \mathrm{~cm}^{-1}$ also for the SOA formation and reaction at $0 \%$ relative humidity. This absorption can be allocated to alcohols or carboxylic acids, but in case of the photochemical treatment with chlorine also to the $v(\mathrm{C}-\mathrm{Cl})$ vibration (Socrates, 1980). Similar absorptions are observed for SOA from guaiacol and $\alpha$-pinene, but weaker. From the photochemical reaction with bromine, an additional absorption, 
Table 1. Assignment of measured absorptions to functional groups from SOA reacting with RHS using long-path absorption FTIR spectroscopy (L: simulated sunlight at $0 \%$ relative humidity; LW: simulated sunlight at $25 \%$ relative humidity; w: weak; s: strong; $\downarrow$ : destruction; $\uparrow$ : formation).

\begin{tabular}{|c|c|c|c|c|c|c|c|c|}
\hline \multirow[b]{2}{*}{ mode } & \multirow[b]{2}{*}[\mathrm{cm}^{-1}]{} & \multirow[b]{2}{*}{ assignment } & \multicolumn{2}{|c|}{ SOA catechol } & \multicolumn{2}{|c|}{ SOA guaiacol } & \multicolumn{2}{|c|}{ SOA $\alpha$-pinene } \\
\hline & & & $\mathrm{L}$ & LW & $\mathrm{L}$ & LW & $\mathrm{L}$ & LW \\
\hline \multicolumn{9}{|c|}{ Reaction with RHS from chlorine } \\
\hline$v(\mathrm{C}-\mathrm{H})$ & 3050 & aromatic & $\mathrm{w} \downarrow$ & $\mathrm{w} \downarrow$ & & & & \\
\hline$v(\mathrm{C}-\mathrm{H})$ & $3000-2880$ & aliphatic & & & $\mathrm{s} \downarrow$ & $\mathrm{s} \downarrow$ & $\mathrm{s} \downarrow$ & $\mathrm{s} \downarrow$ \\
\hline$v(\mathrm{H}-\mathrm{Cl})$ & 2887 & gaseous $\mathrm{HCl}$ & $\mathrm{s} \uparrow$ & $\mathrm{w} \uparrow$ & $\mathrm{w} \uparrow$ & $\mathrm{w} \uparrow$ & $\mathrm{w} \uparrow$ & $\mathrm{w} \uparrow$ \\
\hline$v(\mathrm{C}=\mathrm{O})$ & 2349 & $\mathrm{CO}_{2}$ & $\mathrm{~s} \uparrow$ & $\mathrm{s} \uparrow$ & $\mathrm{s} \uparrow$ & $\mathrm{s} \uparrow$ & $\mathrm{s} \uparrow$ & $\mathrm{s} \uparrow$ \\
\hline$v(\mathrm{C}=\mathrm{O})$ & 2143 & $\mathrm{CO}$ & $\mathrm{w} \downarrow$ & $\mathrm{w} \downarrow$ & $\mathrm{w} \uparrow$ & $\mathrm{w} \uparrow$ & $\mathrm{w} \uparrow$ & $\mathrm{w} \uparrow$ \\
\hline$v(\mathrm{C}-\mathrm{O})$ & 1106 & formic acid? & $\mathrm{s} \downarrow$ & $\mathrm{s} \downarrow$ & $\mathrm{s} \downarrow$ & $\mathrm{s} \downarrow$ & $\mathrm{w} \uparrow$ & $\mathrm{w} \uparrow$ \\
\hline$\nu_{\text {as }}(\mathrm{C}-\mathrm{Cl})$ & 851 & phosgene? & $\mathrm{w} \uparrow$ & $\mathrm{w} \uparrow$ & & & & \\
\hline$\delta(\mathrm{O}=\mathrm{C}=\mathrm{O})$ & 668 & $\mathrm{CO}_{2}$ & $\mathrm{~s} \uparrow$ & $\mathrm{s} \uparrow$ & $\mathrm{s} \uparrow$ & $\mathrm{s} \uparrow$ & $\mathrm{s} \uparrow$ & $\mathrm{s} \uparrow$ \\
\hline \multicolumn{9}{|c|}{ Reaction with RHS from bromine } \\
\hline$v(\mathrm{C}-\mathrm{H})$ & 3050 & aromatic & $\mathrm{s} \downarrow$ & $\mathrm{s} \downarrow$ & & & & \\
\hline$v(\mathrm{C}-\mathrm{H})$ & $3000-2880$ & aliphatic & & & $\mathrm{w} \downarrow$ & $\mathrm{w} \downarrow$ & $\mathrm{s} \downarrow$ & $\mathrm{w} \downarrow$ \\
\hline$v(\mathrm{H}-\mathrm{Br})$ & 2559 & gaseous $\mathrm{HBr}$ & $\mathrm{w} \uparrow$ & $\mathrm{w} \uparrow$ & $\mathrm{s} \uparrow$ & $\mathrm{w} \uparrow$ & $\mathrm{w} \uparrow$ & $\mathrm{w} \uparrow$ \\
\hline$v(\mathrm{C}=\mathrm{O})$ & 2349 & $\mathrm{CO}_{2}$ & $\mathrm{~s} \uparrow$ & $\mathrm{s} \uparrow$ & $\mathrm{s} \uparrow$ & $\mathrm{s} \uparrow$ & $\mathrm{s} \uparrow$ & $\mathrm{s} \uparrow$ \\
\hline$v(\mathrm{C}=\mathrm{O})$ & 2143 & $\mathrm{CO}$ & $\mathrm{s} \uparrow$ & $\mathrm{w} \uparrow$ & $\mathrm{s} \uparrow$ & $\mathrm{s} \uparrow$ & $\mathrm{s} \uparrow$ & $\mathrm{s} \uparrow$ \\
\hline$v(\mathrm{C}-\mathrm{O})$ & 1106 & formic acid? & $\mathrm{w} \uparrow$ & & $\mathrm{w} \downarrow$ & $\mathrm{w} \uparrow$ & $\mathrm{s} \uparrow$ & $\mathrm{w} \uparrow$ \\
\hline$\delta(\mathrm{O}=\mathrm{C}=\mathrm{O})$ & 668 & $\mathrm{CO}_{2}$ & $\mathrm{~s} \uparrow$ & $\mathrm{s} \uparrow$ & $\mathrm{s} \uparrow$ & $\mathrm{s} \uparrow$ & $\mathrm{s} \uparrow$ & $\mathrm{s} \uparrow$ \\
\hline
\end{tabular}
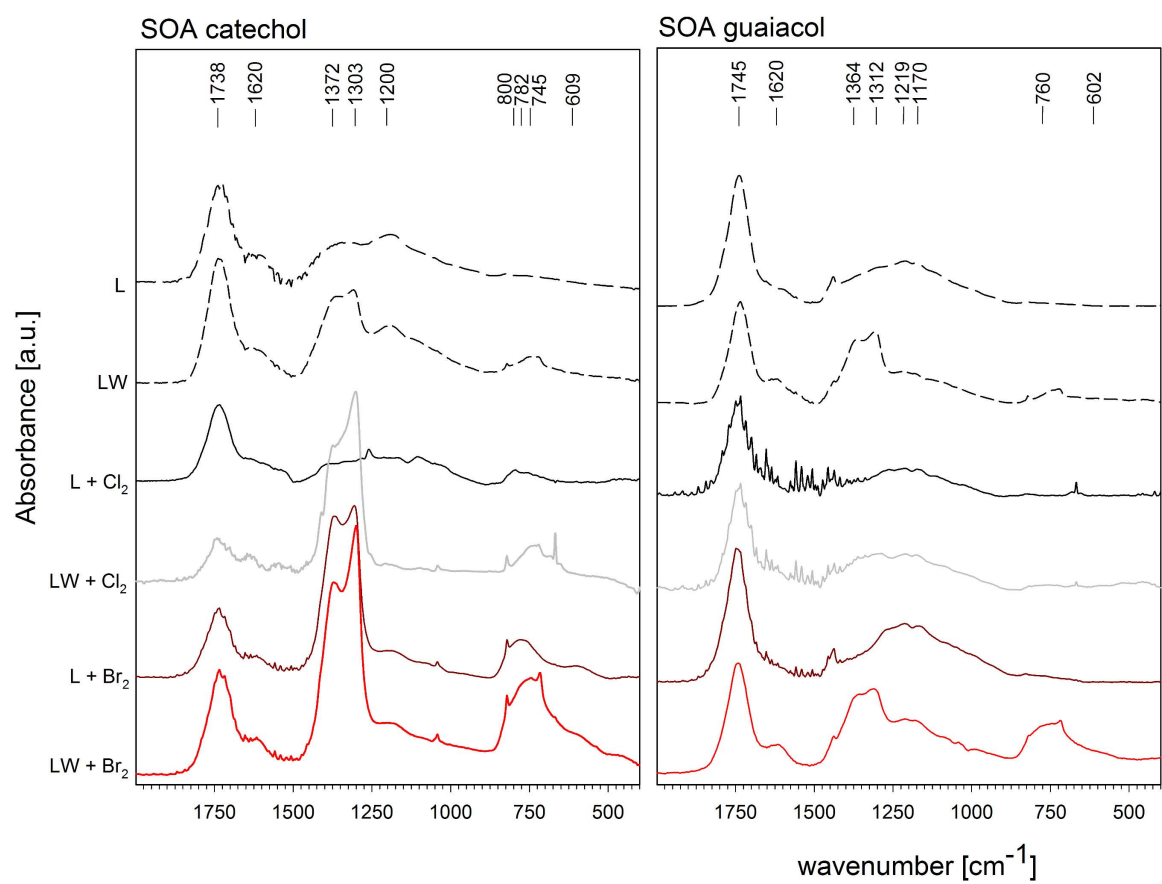

SOA $\alpha$-pinene

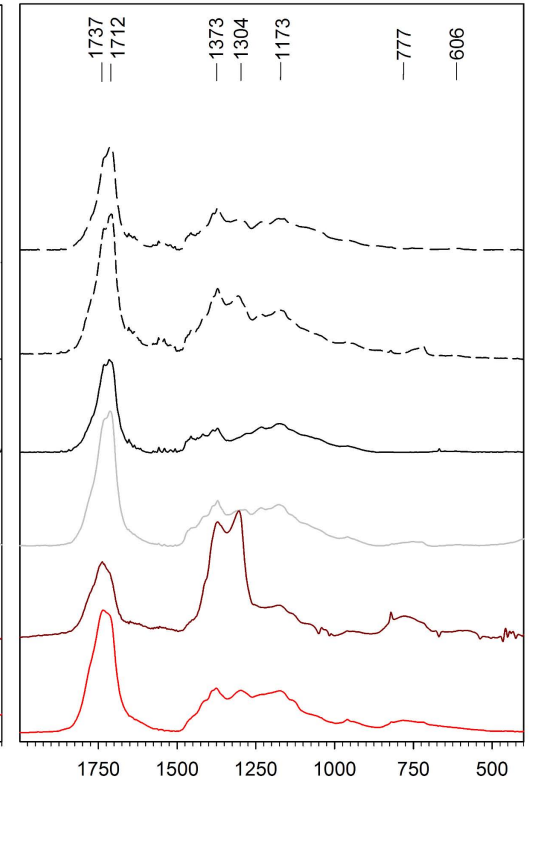

Fig. 5. ATR-FTIR spectra of unprocessed SOA $(\mathrm{L}+\mathrm{LW})$ (Ofner, 2011) and SOA processed with $\mathrm{RHS}\left(\mathrm{L}+\mathrm{Cl}_{2}, \mathrm{LW}+\mathrm{Cl}_{2}, \mathrm{~L}+\mathrm{Br}_{2}\right.$ and $\mathrm{LW}+\mathrm{Br}_{2}$ ); L: SOA formed with simulated sunlight at $0 \%$ relative humidity; LW: SOA formed with simulated sunlight at $25 \%$ relative humidity; L(W) + halogen: preformed SOA at L(W) condition, processed with RHS formed from the photolyzed molecular halogen species. 
Table 2. Relative amount of halogenated compounds (compared to the not halogenated bulk) and basic aerosol parameters like O/C and H/C ratios as well as the averaged carbon oxidation state $\overline{\mathrm{OS}_{\mathrm{C}}}$ (where $n_{\mathrm{c}}$ is the related number of carbon atoms) observed in samples from the molecular photochemical reaction experiments (derived by ICR-FT/MS).

\begin{tabular}{|c|c|c|c|c|c|c|}
\hline Sample and reaction & $\mathrm{CHOCl}$ & $\mathrm{CHOBr}$ & $\mathrm{O} / \mathrm{C}$ & $\mathrm{H} / \mathrm{C}$ & $\overline{\mathrm{OS}_{\mathrm{C}}}$ & $n_{\mathrm{c}}$ \\
\hline \multicolumn{7}{|l|}{ SOA from catechol } \\
\hline Chlorinated & $3 \%$ & & $0.31-0.67$ & $0.81-1.08$ & $0.3-2$ & $10-27$ \\
\hline Brominated & & $30 \%$ & $0.55-1.2$ & $0.9-1.67$ & $0.3-2$ & $5-35$ \\
\hline \multicolumn{7}{|l|}{ SOA from guaiacol } \\
\hline Chlorinated & $15 \%$ & & $0.31-0.67$ & $0.6-1.08$ & $0.3-2$ & $8-22$ \\
\hline Brominated & & $53 \%$ & $0.6-1.2$ & $0.9-1.67$ & $0.1-1.8$ & $5-35$ \\
\hline \multicolumn{7}{|l|}{ SOA from $\alpha$-pinene } \\
\hline Chlorinated & $33 \%$ & & $0.33-0.54$ & $1.31-1.67$ & $0.5-1.5$ & $7-30$ \\
\hline Brominated & & $66 \%$ & $0.42-0.83$ & $1.18-2$ & $0.5-1.3$ & $6-35$ \\
\hline
\end{tabular}

Table 3. Relative amount of halogenated compounds (compared to the not halogenated bulk) observed by ICR-FT/MS in samples of SOA interacting with RHS released from the simulated salt-pan.

\begin{tabular}{lcc}
\hline SOA sample & $\mathrm{CHOCl}$ & $\mathrm{CHOBr}$ \\
\hline SOA from catechol & $46 \%$ & $23 \%$ \\
SOA from guaiacol & $52 \%$ & $23 \%$ \\
SOA from $\alpha$-pinene & $32 \%$ & $40 \%$ \\
\hline
\end{tabular}

which can be assigned to the $v(\mathrm{C}-\mathrm{Br})$ vibration, is observed at $609-602 \mathrm{~cm}^{-1}$ (for all three types of SOA). Hence, most significant changes of the vibrational spectra of organic aerosols by treatment with RHS are observed for the reaction with bromine, influencing carboxylic acids and forming absorptions in the $v(\mathrm{C}-\mathrm{Br})$ region.

\subsection{Determination of the degree of halogenation of the particulate phase}

ICR-FT/MS was used in negative electrospray ionization mode to ionize most of these polar acidic compounds. The degree of halogenation as well as the main $\mathrm{O} / \mathrm{C}$ and $\mathrm{H} / \mathrm{C}$ ratios (Schmitt-Kopplin et al., 2010) and the averaged carbon oxidation state $\left(\overline{\mathrm{OS}_{\mathrm{C}}}\right)$ values (Kroll et al., 2011) were calculated. For the molecular halogen photochemical experiments, the amount of halogenated compounds related to the unprocessed aerosol mass were deduced (Table 2). These calculations exhibit an increase of halogenated compounds with a decrease of aromaticity. While SOA from catechol only exhibits $30 \%$ of all brominated compounds, SOA from $\alpha$ pinene exhibits $66 \%$. Further $\mathrm{O} / \mathrm{C}$ and $\mathrm{H} / \mathrm{C}$ values are reported in this table, based on $0.1 \mathrm{ppm}$ mass accuracy calculated CHOS elementary compositions (see Fig. 6 for the nominal mass 319 from unprocessed and halogenated SOA from catechol), as described for aerosol samples elsewhere
(Schmitt-Kopplin et al., 2010). These ratios do not significantly differ from reported values of the unprocessed organic aerosols with very similar van Krevelen-diagram characteristics as previously described (Ofner et al., 2011), and the $\mathrm{Br}$-compounds always covered the same large $\mathrm{CHO}$ area in the van Krevelen diagrams while the $\mathrm{Cl}$-compounds showed lower compound amounts in specific positions (Fig. 7 - van Krevelen diagrams of processed SOA from $\alpha$-pinene). This confirms a high reactivity of $\mathrm{Br}$ towards most $\mathrm{CHO}$ compounds without high specific reactivity of particular chemical substructures in the mixture such as observed with $\mathrm{Cl}$. The $\overline{\mathrm{OS}_{\mathrm{C}}}$ values of halogenated aerosols exhibit an increase of the oxidation state up to 2, while the entire organic aerosols do not reach oxidation states higher than 1 (Fig. 8). For the photochemical halogenation reaction with chlorine, halogenated compounds exhibit rather low numbers of carbon atoms. Brominated compounds are found over the whole range of carbon atoms, based on the non-halogenated aerosol. ICRFT/MS confirms the formation of a large number of halogenated compounds towards high molecular weights in the particle phase of processed SOA.

\section{Results from combined SOA - salt-pan experiments}

Results from the molecular halogen photochemical experiments were used to determine changes of the physicochemical properties of SOA, caused by RHS released from the simulated salt pan.

\subsection{Change of aerosol size-distribution}

RHS released from the simulated salt-pan experiments influence the aerosol size-distribution of SOA similar to those in the molecular halogen photochemical experiments (Fig. 9). An increase of the mean particle diameters was observed for all three types of model SOA, reacting with RHS from the 


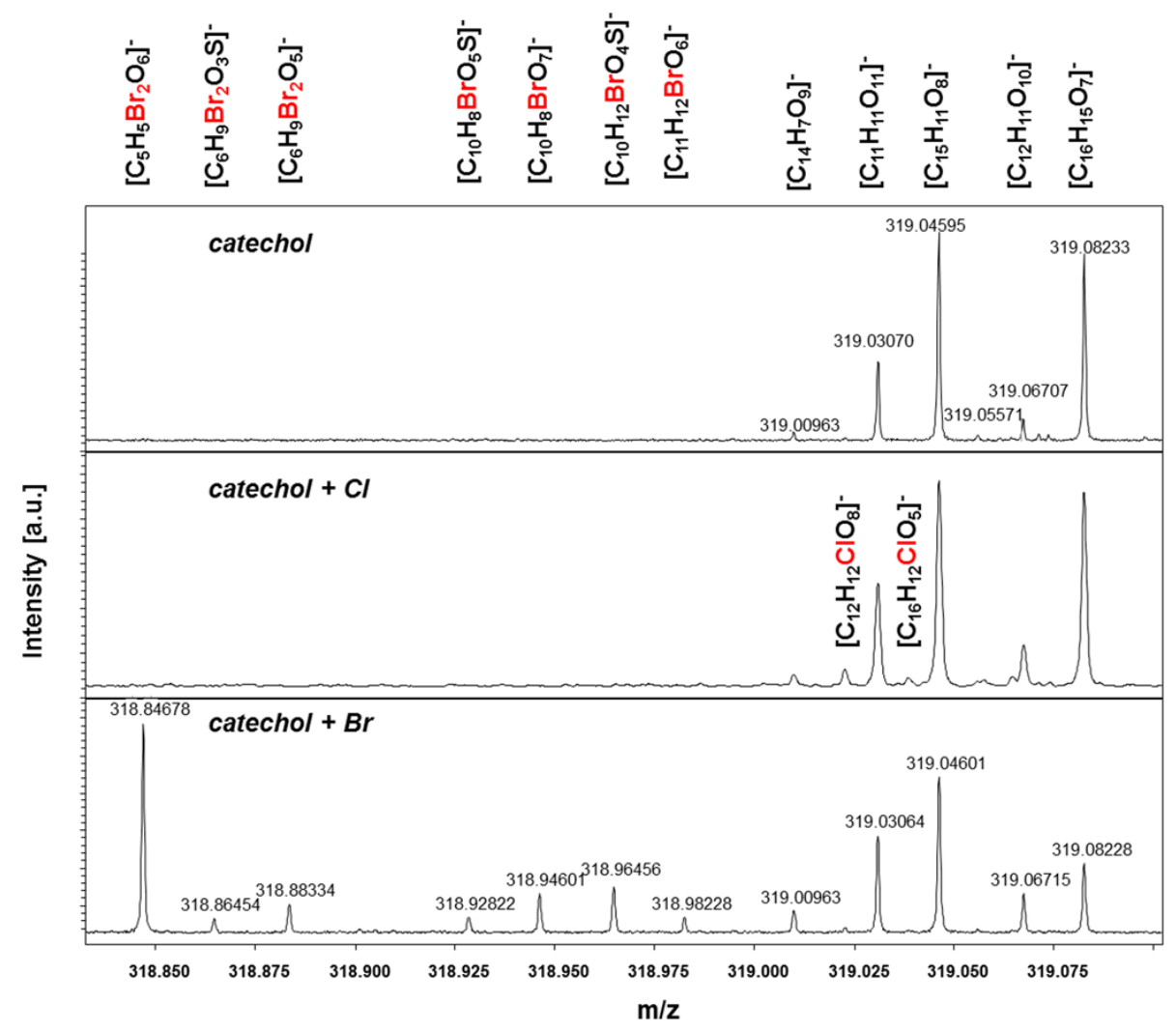

Fig. 6. ICR-FT/MS nominal mass 319 with detailed halogenations with $\mathrm{Cl}$ and $\mathrm{Br}$ exemplified with catechol.
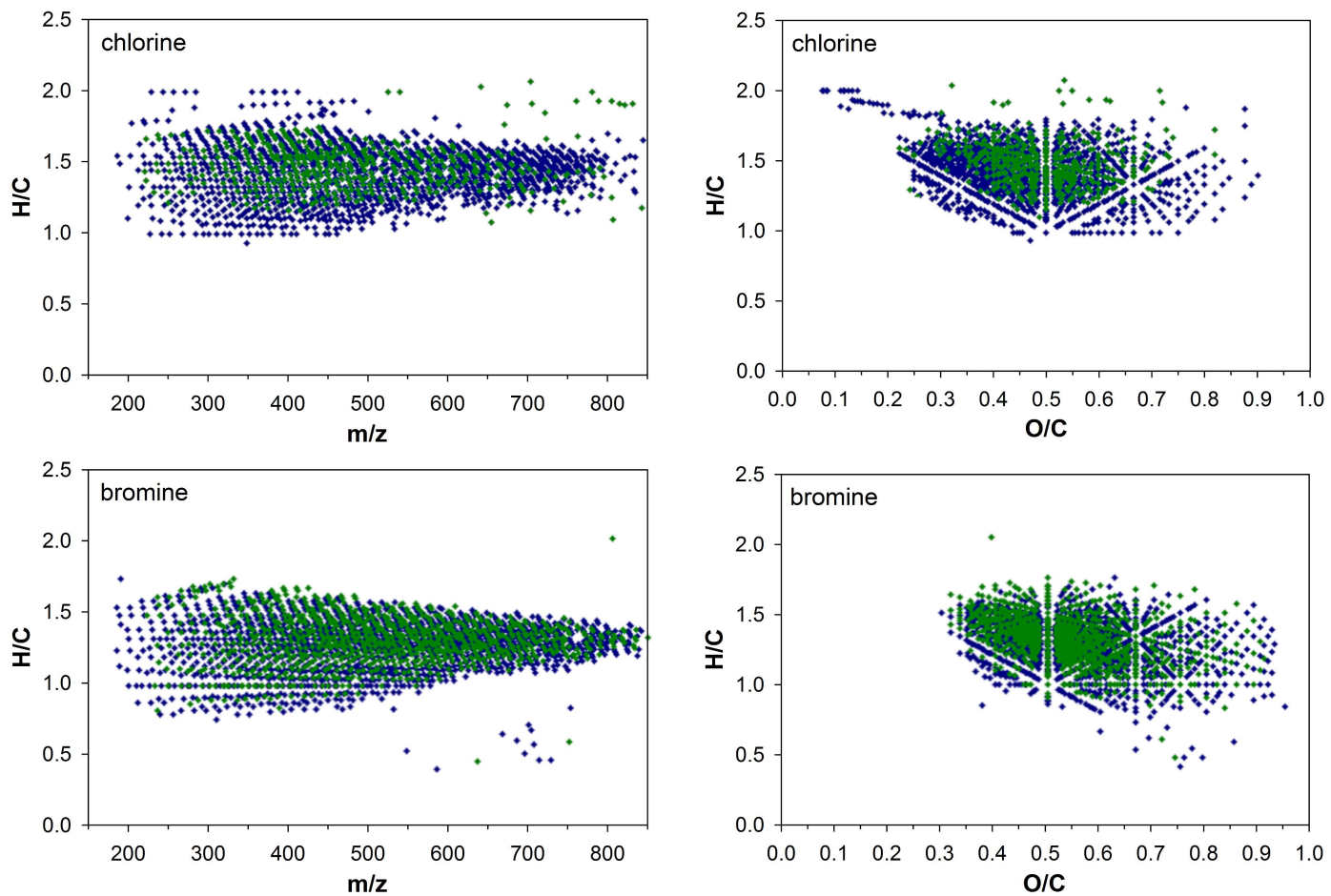

Fig. 7. van-Krevelen diagrams of SOA from $\alpha$-pinene photochemically processed with chlorine and bromine (green - halogenated species; blue - unprocessed SOA). 

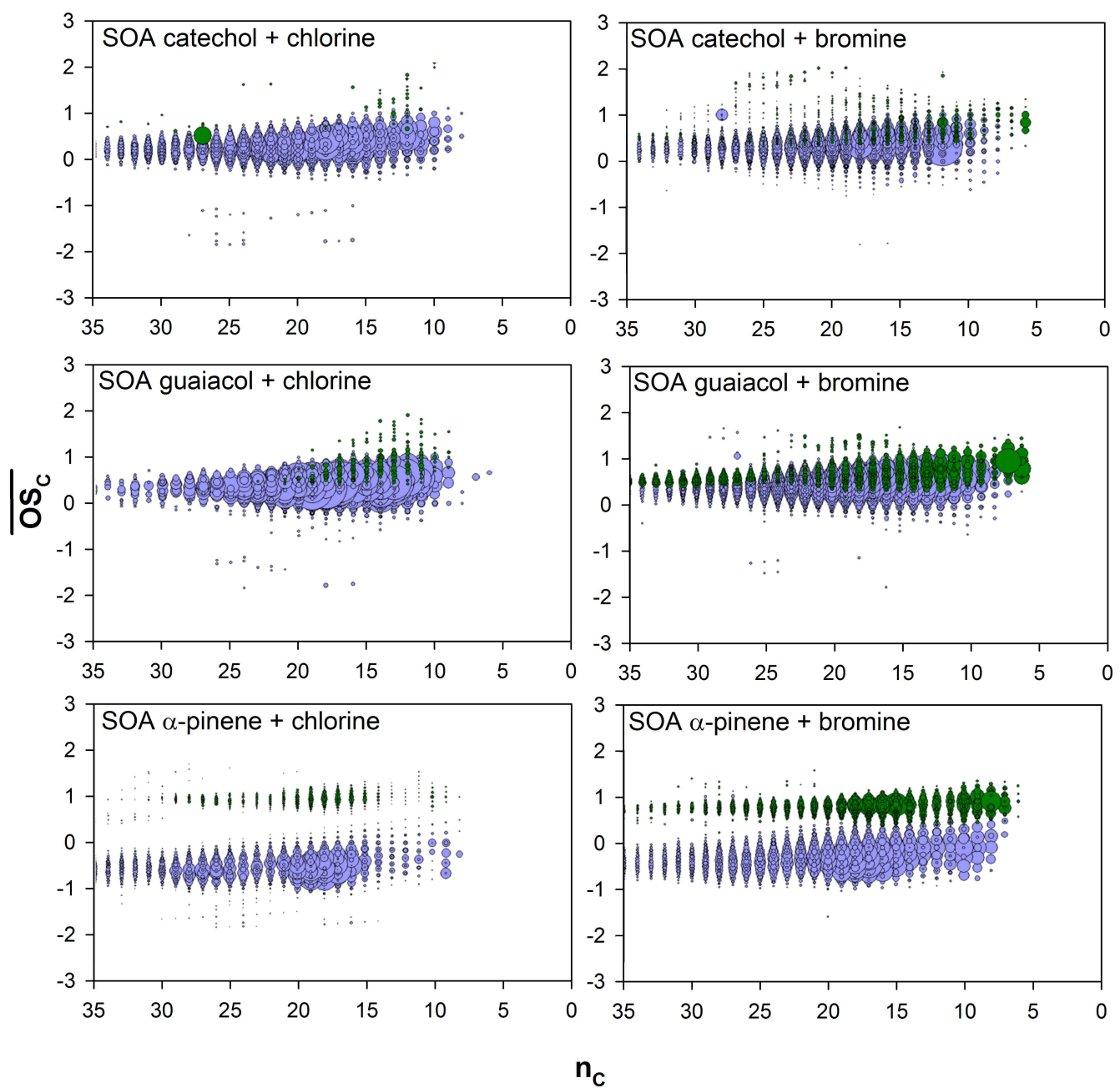

Fig. 8. Averaged carbon oxidation state $\left(\overline{\mathrm{OS}_{\mathrm{C}}}\right)$ as a function of the number of carbon atoms $n_{\mathrm{c}}$ : unprocessed SOA (blue), halogenated species in the particle phase (green). The SOA was formed and processed in the presence of simulated sunlight at $0 \%$ relative humidity. The bubble size expresses the signal intensity from the experimental data.

salt pan. Although the relative humidity in the smog chamber in combined experiments is about $60 \%$ (maximum for molecular halogen photochemical experiments was $25 \%$ ), this effect can be related to the influence of RHS on SOA.

\subsection{Optical properties in the UV/VIS range}

SOA processed by RHS released from the simulated salt pan exhibits similar diffuse-reflectance UV/VIS spectra compared with the spectra derived from SOA processed by molecular halogen species. To achieve detailed changes in the diffuse-reflectance UV/VIS absorption spectra, the differential absorbance was calculated according to Eq. (1). The coefficients for normalization at $200 \mathrm{~nm}$ are about $15 \%$ of the original values. All three SOA samples exhibit both features observed for the molecular halogen photochemical experiments with chlorine and bromine (Fig. 10). An increase of the differential absorbance is observed for all three differ- ent model aerosols in the spectral range around $250 \mathrm{~nm}$. A decrease in $\mathrm{dA}$ is observed above $380 \mathrm{~nm}$ for all three samples, which is strongest for the processed SOA from catechol. Hence, a bleaching is observed for all samples, which is strongest for the aromatic SOA from catechol. This bleaching is a strong hint at a removal of conjugated double bonds and the dominance of chlorinated organic matter in the processed SOA.

\subsection{Changes of vibrational features of particulate matter}

Caused by the low precursor concentrations, which had to be used to avoid disturbance of the DOAS system installed in the smog chamber, only small samples of particles could be collected using the method of direct electrostatic precipitation onto the ATR crystal (Ofner et al., 2009). The resulting ATR-FTIR spectra are shown in Fig. 11. 


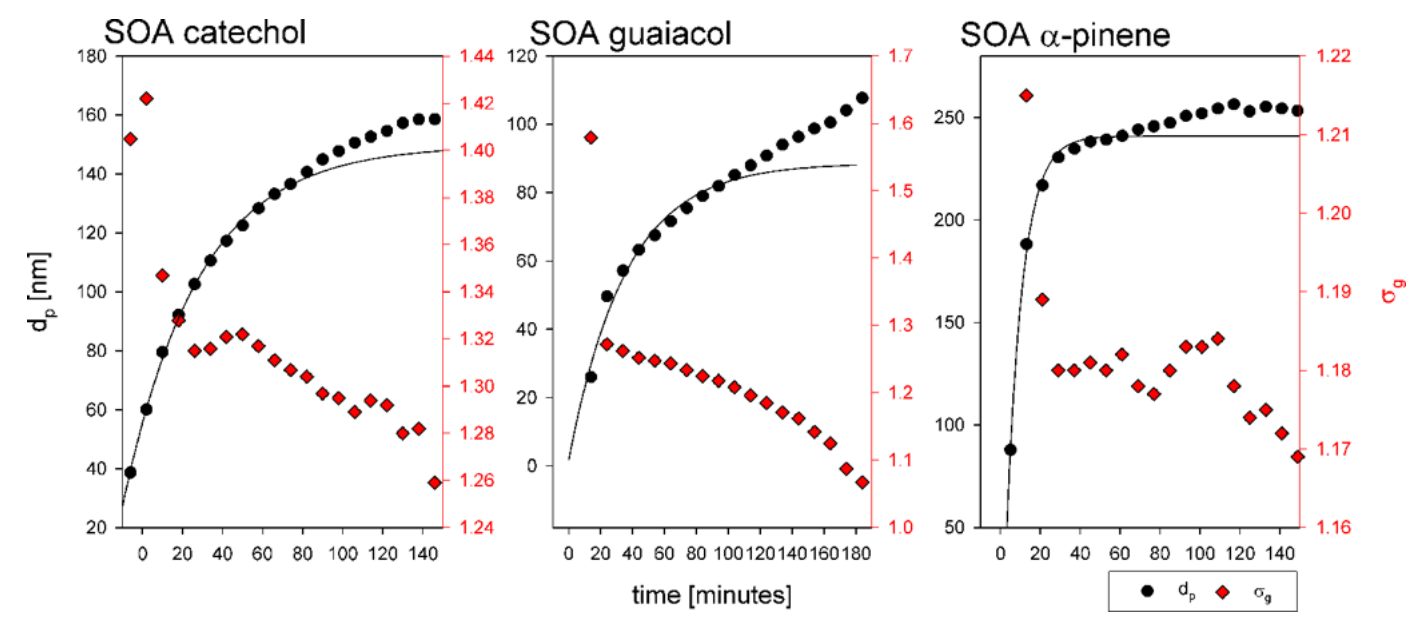

Fig. 9. Evolution of the mean particle diameter $\left(d_{\mathrm{p}}\right)$ and the related geometric standard deviation $\left(\sigma_{\mathrm{g}}\right)$ of SOA from the different model aerosols while interacting with RHS released from the simulated salt pan.
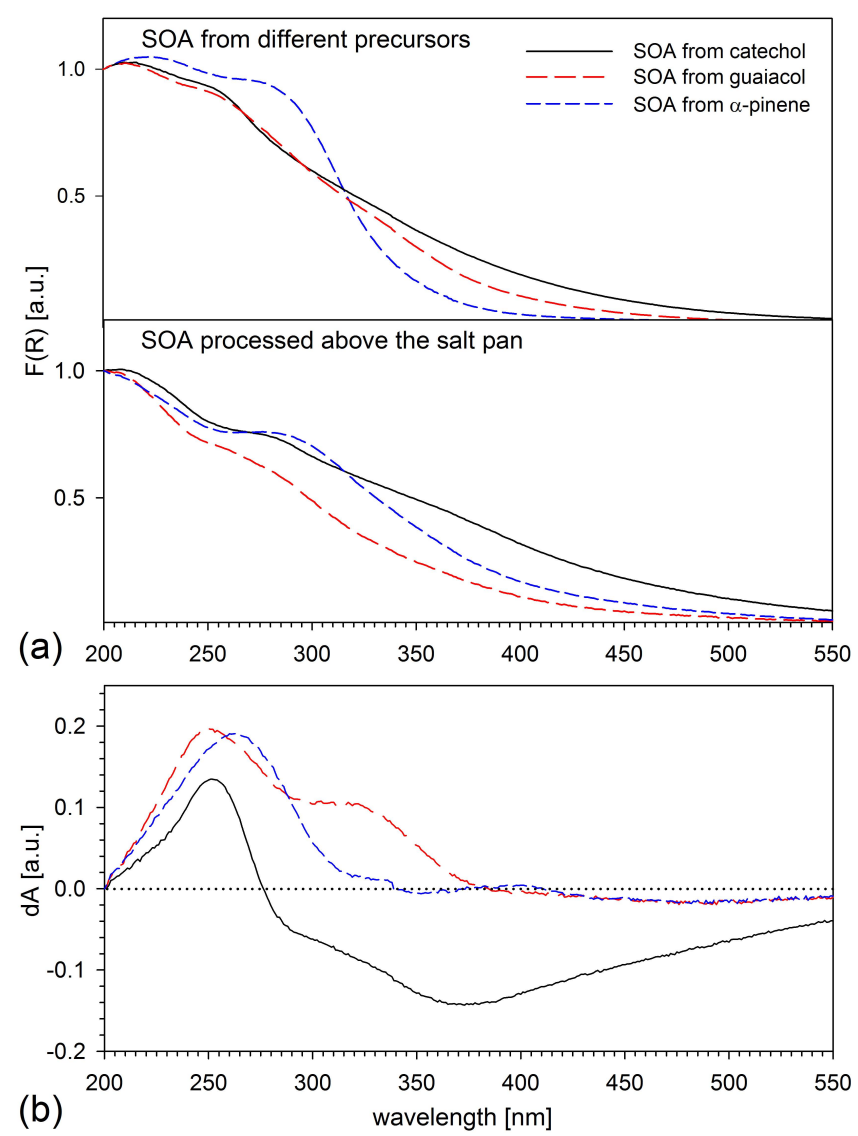

Fig. 10. Single absorption spectra $F(R)$ (a) and change of the differential absorbance (dA) (b) in the UV/VIS region due to the reaction of the organic aerosols with RHS released from the simulated salt pan, indicating a chlorination of the SOA (by comparison with Fig. 3).

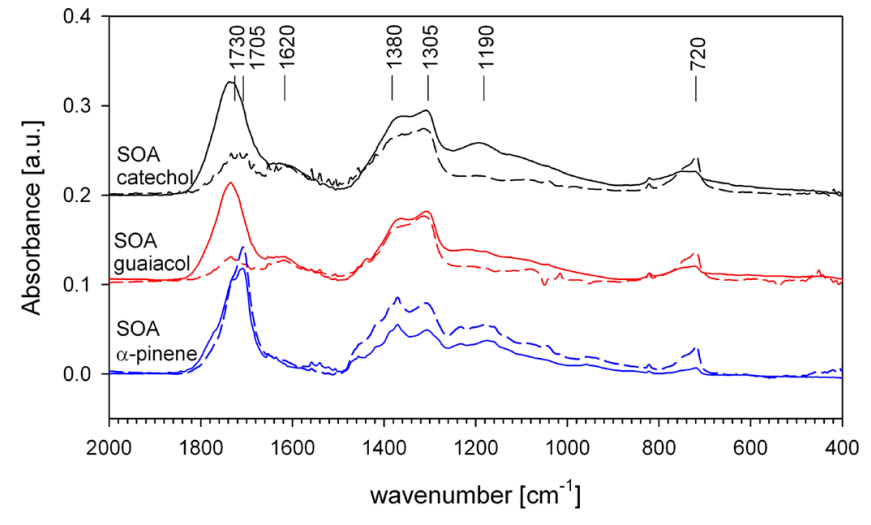

Fig. 11. ATR-FTIR spectra of the unprocessed SOA models (solid line) and processed with RHS (dashed line) released from the simulated salt pan, respectively.

For the salt pan RHS exposure experiments, a strong dominance of two absorptions at about 1380 and $1305 \mathrm{~cm}^{-1}$ is visible in the vibrational spectra. The absorption of the carbonyl $v(\mathrm{C}=\mathrm{O})$-vibration decreases for SOA from catechol and guaiacol. Only SOA from $\alpha$-pinene exhibits a strong $v(\mathrm{C}=\mathrm{O})$ at about $1705 \mathrm{~cm}^{-1}$. This persistence of the carbonyl stretch region in processed SOA from $\alpha$-pinene was also observed in the molecular halogen photochemical experiments.

All three SOA samples exhibit a rather medium to strong, broad band at about $720 \mathrm{~cm}^{-1}$ and above. This absorption might be assigned to the $v(\mathrm{C}-\mathrm{Cl})$ vibration and indicates a possible halogenation of the organic aerosol. The shape of this band and the fact that it has exactly the same position for all three organic aerosols can be explained by a halogenation process involving only one specific halogen species reacting with the same structural or functional feature present in all three different SOAs (e.g. carboxylic acids). A contribution of other structural features of the organic aerosols to 


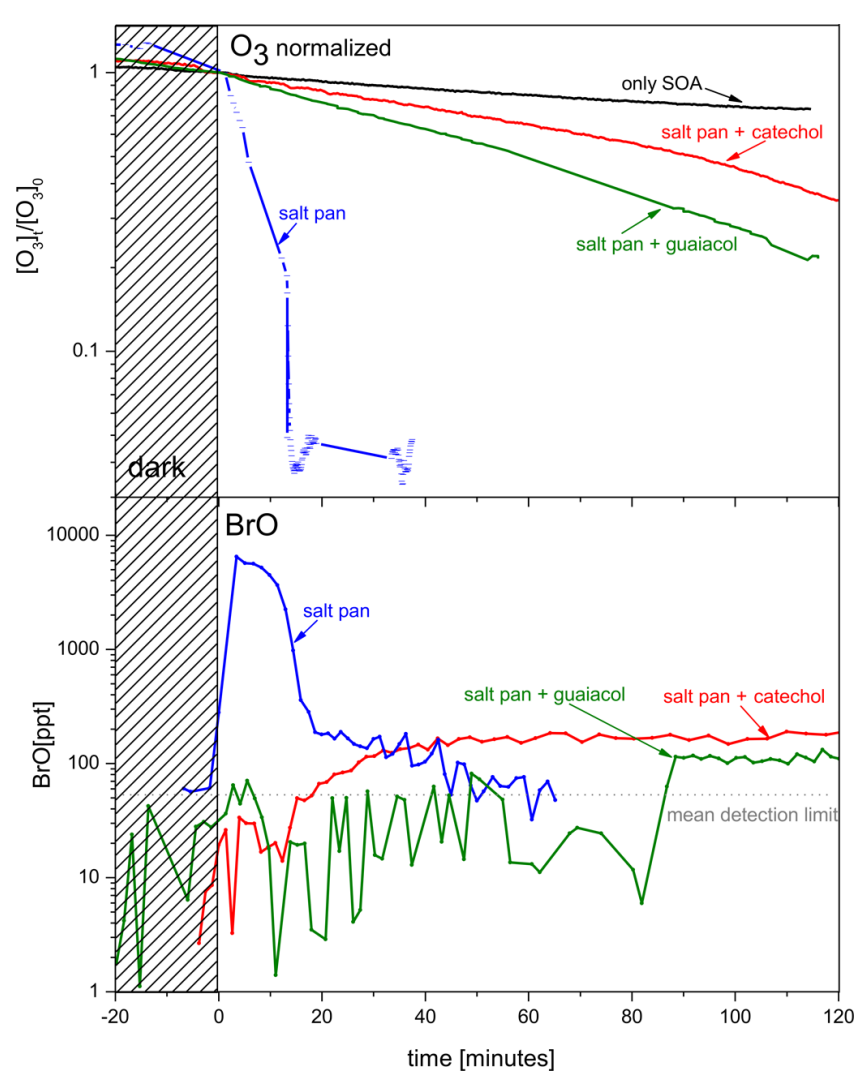

Fig. 12. Time series of ozone (top) and BrO (bottom) show the influence of SOA from catechol and guaiacol on the release of RHS from the simulated salt pan. Ozone values are normalized to the $\mathrm{O}_{3}$ mixing ratios at $t=0$. The experiments were carried out at $60 \% \mathrm{RH}$. During an experiment, where only the salt pan without SOA precursor was exposed to simulated sunlight (blue lines, from Buxmann et al., 2012), ozone was destroyed within less than $20 \mathrm{~min}$ and more than $6000 \mathrm{ppt} \mathrm{BrO}$ were formed. Measurements of $\mathrm{O}_{3}$ were performed only for limited periods of time (indicated by horizontal bars), to reduce dilution. During experiments with SOA precursors (indicated in red, green and black) ozone decay was much slower. $\mathrm{BrO}$ exceeds the mean detection limit of $57 \mathrm{ppt}$ with a time delay (after the solar simulator was switched on at $t=0$ ) of $18 \mathrm{~min}$ for catechol and $87 \mathrm{~min}$ for guaiacol. Maximum $\mathrm{BrO}$ mixing ratios of less than 200 ppt were observed, one order of magnitude lower than without SOA.

this absorption is also likely and therefore, this band cannot be exactly allocated to halogenated species.

Concluding from the observations concerning the molecular processing experiments, a reaction of carboxylic groups with subsequent formation of carbon-chlorine bonds is likely but not confirmed. The formation of carbon-bromine bonds, which would result in absorptions between 600 and $650 \mathrm{~cm}^{-1}$, was not observed.

\subsection{Determination of the degree of halogenation of the particulate phase}

The acquisition of ultrahigh-resolution mass spectra of SOA processed with halogens released from the salt pan was impeded by matrix effects and the low organic aerosol content of the samples. Thus, only the calculated percentage of $\mathrm{CHOCl}$ - and $\mathrm{CHOBr}$-containing species relative to the $\mathrm{CHO}-$ containing species is presented in Table 3. Due to the fact that not the total mass range was evaluated, the presented amounts of halogenated compounds in Table 3 give only hints at the halogenation processes which have taken place. Nevertheless, organic aerosols interacting with gaseous halogen species released from the salt pan contain high amounts of halogenated organic compounds. In contrast to the molecular halogen photochemical experiments and, as expected by the evolution of the aerosol size distribution, the differential UV/VIS-absorption, and ATR-FTIR-spectra, chlorination seems to be more important than bromination. Up to $52 \%$ of chlorinated compounds in relation to $100 \%$ of non-halogenated compounds could be measured in organic aerosol from guaiacol.

\subsection{Influence of the presence of SOA on the halogen release from the simulated salt-pan}

While the mechanism of halogen release from the salt pan causes a rapid ozone depletion within $20 \mathrm{~min}$ and corresponding $\mathrm{BrO}$ formation of up to $6 \mathrm{ppb} \mathrm{BrO}$ (Buxmann et al., 2012), the organic aerosol appears to inhibit this process (Fig. 12). Ozone depletion is slowed down, and only less than $10 \%$ of $\mathrm{BrO}$ of the expected values are observed during experiments with SOA formation from catechol and guaiacol. During experiments without SOA precursors the $\mathrm{BrO}$ formation started immediately after the solar simulator was switched on, with an initial rate of up to $\mathrm{d}[\mathrm{BrO}] / \mathrm{dt}_{\text {initial }}=$ $40 \mathrm{ppt} \mathrm{s}^{-1}$ (Buxmann et al., 2012). The BrO formation in the presence of SOA was delayed: $\mathrm{BrO}$ exceeds the mean detection limit of $56 \mathrm{ppt}$ after $18 \mathrm{~min}$ and $87 \mathrm{~min}$ with catechol and guaiacol as precursors, respectively. The mean particle diameter reached $80 \mathrm{~nm}$ for both precursor substances at that time (catechol SOA formation is faster, as particle formation already occurs during the dark phase). This is a hint that interaction of $\mathrm{BrO}$ precursors (e.g. Br) with the organic substances already occurs with small particles or in the gas phase, but the involved reactions were not identified so far. Due to Mie-scattering (caused by SOA formation from $\alpha$ pinene, where the mean particle diameter was about $250 \mathrm{~nm}$ ), the detection limit of the DOAS instrument was poor. No $\mathrm{BrO}$ was observed during experiments with $\alpha$-pinene above a detection limit of 200 ppt. During all salt pan experiments presented in this study, no chlorine atoms could be found in the presence as well as in the absence of organic aerosols above a mean detection limit of $5 \times 10^{4}$ molecules $\mathrm{cm}^{-3}$ or $0.002 \mathrm{ppt}$ of the radical clock measurements. In general, 
primary $\mathrm{Br}_{2}$ release is favored as compared to $\mathrm{BrCl}$ and $\mathrm{Cl}_{2}$ release from sodium halide substrates (e.g. Behnke et al., 1999; Sjostedt and Abbatt, 2008), but formation of chlorinated compounds is possible (e.g. Behnke and Zetzsch, 1990). However, chlorination was dominating in the particulate phase over bromination during our studies, as mentioned above. It is well known that $\mathrm{Br}$ atoms mainly react with unsaturated hydrocarbons or partly oxidized species (e.g. aldehydes), whereas $\mathrm{Cl}$ atoms react with saturated hydrocarbons as well (e.g. Atkinson et al., 2006).

\section{Discussion}

In general, halogens influence several properties of organic aerosols, but different types of SOA exhibit different transformations. The reactions depend not only on the SOA precursor (and thus on the chemical composition of the organic aerosol) but also on the halogen species and the experimental conditions, which can even change the predominant halogenated species.

\subsection{Molecular halogen photochemical experiments}

Chlorine species cause a strong increase of the mean particle diameters, and in the case of ether groups, the formation of a second mode was observed. Therefore, the increase in particle diameter can be explained by the formation of low-volatile species in the surrounding gas phase, condensing onto the already present particles. Due to this effect, atmospheric halogen species might also exhibit an aerosolformation potential as soon as the oxidation capacity, based on ozone and $\mathrm{OH}$ radicals, of the atmosphere is insufficient to produce further low-volatile compounds. The effect of bromine species on the aerosol size distributions is weaker than observed for chlorine. In fact, bromine is able to reduce the mean particle diameter, as observed for SOA from $\alpha$-pinene. This effect can be explained by halogen species not only forming new low-volatile compounds, thus contributing to existing particles or forming new particles, but also changing the chemical structure and functional groups and thus related volatility and hydrophilic properties of the particulate matter itself. Due to the fact that the mean particle diameter increases during the reaction of SOA with halogens, a decrease of the saturation vapor pressure, caused by the reaction of RHS with SOA, is assumed.

The latter statement is underlined by the observation of the formation of various gaseous species due to the interaction of halogens with organic aerosols. Long-path absorption spectra indicate the formation of additional amounts of $\mathrm{CO}_{2}, \mathrm{CO}$, and $\mathrm{HCl}$ or $\mathrm{HBr}$. At the same time, a decrease in $v(\mathrm{C}-\mathrm{H})_{\text {aromatic }}$ and $v(\mathrm{C}-\mathrm{H})_{\text {aliphatic }}$ of the particle phase was observed. Atomic chlorine induced hydrogen abstraction can explain the simultaneous formation of $\mathrm{HCl}$ and the decrease of $v(\mathrm{C}-\mathrm{H})$. Thus, $\mathrm{C}-\mathrm{H}$ bonds are destroyed. This is known to be the case for the reaction of chlorine with aliphatic compounds, but also bromine species show this behavior. Therefore, the observations might be explained by the reaction of $\mathrm{BrO}$ or $\mathrm{HOBr}$ with $\mathrm{C}-\mathrm{H}$ bonds.

The spectra of the particulate matter of the organic aerosol itself also exhibit strong changes. While the carbonyl $v(\mathrm{C}=\mathrm{O})$ band is the most dominant vibration of the unprocessed aerosols, this vibration is less important after the reaction with halogens. This decrease can also be observed for the $v(\mathrm{C}=\mathrm{C})$ of the aromatic aerosols. The $v(\mathrm{C}-\mathrm{Cl})$ and the $v(\mathrm{C}-\mathrm{Br})$ stretching vibrations indicate the presence of halogenated compounds, even though the assignment of the vibrations to specific compounds was not possible. Also $v(\mathrm{O}-$ Cl) (Evans et al., 1965) and spectral features of structural elements (Socrates, 1980) can be found in this spectral region. Most dominant are bands observed at about 1370 and $1300 \mathrm{~cm}^{-1}$. The assignment of those absorptions is difficult. Based on the observation that these bands are observed for halogenation processes with chlorine as well as with bromine at the same position, the influence of a functional group or a structural element is more likely than the formation of a halogenated compound. Therefore, a link of these absorptions with carboxylic acids, carboxylic acid halides, or derivates is likely but not confirmed.

The transformations of the particulate matter also affect the optical properties of the aerosols in the UV/VIS spectral range. While the reaction with chlorine causes a bleaching of the particles, the reaction with bromine causes a higher absorbance towards higher wavelengths - the particulate phase appears "golden".

High amounts of brominated and chlorinated compounds could be identified in the particulate matter of the organic aerosols using ICR-FT/MS. Halogenated SOA exhibits higher average carbon oxidation states than the unprocessed aerosols. Thus, the reaction of RHS with SOA causes a further oxidation of the organic matter of the aerosols, even when the surrounding atmosphere containing ozone and hydroxyl radicals is unable to do so.

\subsection{Related mechanisms of halogen chemistry}

A large variety of organic reactions involving different halogen species is known within the basic organic chemistry literature (e.g. March, 1992). Those reactions can be divided into two groups: carbon skeleton affecting and functionality modifying reactions. The halogen species discussed here are the species which are supposed to be present during the molecular halogen photochemical experiments: $X_{2}$, HOX and HX, where $\mathrm{X}$ is chlorine or bromine. XO radicals formed by the rapid reactions of halogen atoms with ozone are considered to be unreactive against the organic precursors and to be converted to $\mathrm{HOX}$ via reaction with $\mathrm{HO}_{2}$, thus keeping the levels low (Mellouki et al., 1994; Bedjanian et al., 2001). The chosen precursors for the SOA represent different structural elements like an aliphatic structure with 
ring strain, comprising primary, secondary and tertiary $\mathrm{C}-\mathrm{H}$ bonds and an olefinic double bond ( $\alpha$-pinene) and substituted aromatic/phenolic structures (catechol and its methyl-ether modification guaiacol), where ring opening upon oxidation and possibly aldol condensation lead to further olefinic and conjugated structures. Those different organic precursors result in a different chemical structure of the related SOA. The SOA is considered to be still highly reactive and thus will offer a different chemical environment for RHS chemistry.

The change of carbon-hydrogen bonds, observed by longpath FTIR spectroscopy upon halogenation (Fig. 4), can be related to the abstraction reaction of $\mathrm{H}$ atoms by chlorine atoms from $\mathrm{C}-\mathrm{H}$ bonds of the methyl groups of the carbon structure (Reaction R1a).

$\mathrm{R}-\mathrm{CH}_{3}+\mathrm{Cl} \cdot \rightarrow \mathrm{R}-\mathrm{CH}_{2} \cdot+\mathrm{HCl}$

Molecular chlorine might then react with the aliphatic radical in the well-known chain propagation of photochlorination according to Reaction (R1b) in the initial phase of chlorine injection.

$\mathrm{R}-\mathrm{CH}_{2} \cdot+\mathrm{Cl}_{2} \rightarrow \mathrm{R}-\mathrm{CH}_{2} \mathrm{Cl}+\mathrm{Cl}$.

Furthermore, addition of a chlorine atom to the aliphatic radical might form saturated carbon-chlorine bonds, as suggested in Fig. 5 if not enough unsaturated/aromatic double bonds for addition are available (see below). On the other hand, the FTIR and UV/VIS spectra indicate the sufficient presence of such sites for addition, and such radical-radical reactions are suppressed due to the high concentration of $\mathrm{O}_{2}$ that quickly leads to the formation of $\mathrm{RO}_{2}$ radicals (Reaction R1c) (Wallington et al., 1989; Carr et al., 2003).

$\mathrm{R}-\mathrm{CH}_{2} \cdot+\mathrm{O}_{2}+\mathrm{M} \rightarrow \mathrm{R}-\mathrm{CH}_{2} \mathrm{O}_{2} \cdot+\mathrm{M}$

The abstraction reaction can concern our model aerosols formed from $\alpha$-pinene and guaiacol (indicated by the longpath FTIR spectra), where methyl groups occur (even more so with the methyl group of guaiacol that has a minor benzylic character because of the lone-pair electrons of the ether oxygen). Abstraction of hydrogen from the two $\mathrm{CH}_{2}$ groups and even more so the tertiary $\mathrm{C}-\mathrm{H}$ bonds of $\alpha$-pinene (if all of them persist in the SOA) is expected as well and indicated by the loss of absorption in Fig. $4\left(2975-2950 \mathrm{~cm}^{-1}\right.$ : hydrogen abstraction from $-\mathrm{CH}_{3} ; 2940-2915 \mathrm{~cm}^{-1}$ : hydrogen abstraction from $-\mathrm{CH}_{2-} ; 2890-2880 \mathrm{~cm}^{-1}$ : hydrogen abstraction from -CH(-)- (Socrates, 1980), corresponding to the weaker bond energies of secondary and tertiary $\mathrm{C}-\mathrm{H}$ bonds). Hydrogen abstraction from methyl groups located close to oxygen or halogen containing functional groups was discussed in detail by Carr et al. (2003).

Halogen addition to unsaturated bonds is the preferred pathway for bromine atoms (Reaction R2) since their abstraction reactions are much slower than those of chlorine atoms. Wallington et al. (1989) studied the addition of atomic bromine to several alkenes. Nordmeyer et al. (1997) studied the chlorination of isoprene and suggested an addition of chlorine to double bonds (Reaction R2) and a quenching of the bond by oxygen (Reaction R1c). A series of unsaturated hydrocarbons were used by Orlando et al. (2003), identifying the same reaction path-way. As indicated by these authors, this reaction is expected to be the most important reaction for formation of brominated compounds from SOA of the chosen precursors. The relative decrease of the aromatic stretch vibration in Fig. 5 of SOA from the aromatic precursors and the atomic composition of brominated species in Fig. 6 support this expectation.

$\mathrm{R}-\mathrm{CH}=\mathrm{CH}-\mathrm{R}+\mathrm{Br} \cdot \rightarrow \mathrm{R}-\mathrm{CBrH}-\mathrm{CH} \cdot-\mathrm{R}$

Bierbach et al. (1996) compared the reaction of chlorine and bromine atoms with the (in our case) competing reaction of $\mathrm{OH}$ radicals. While the reaction with chlorine atoms (hydrogen abstraction) is expected to be faster than the reaction with $\mathrm{OH}$ radicals, the reaction with bromine appears to be in the same temporal regime compared to the reaction with $\mathrm{OH}$ especially for terpenes and dienes. These authors state that the reaction of bromine atoms with especially alkenes and dienes might be an effective tropospheric sink for bromine atoms. The high reactivity of terpenes towards halogenation is indicated by the amount of halogenated compounds related to the organic bulk of SOA from $\alpha$-pinene (Tables 2 and 3 for bromine). The amount of halogenated species caused by reaction of RHS with SOA from the aromatic precursors is significantly lower.

Atomic bromine is also known to abstract hydrogen atoms at tertiary $\mathrm{C}-\mathrm{H}$ bonds (Reaction 3 ).

$$
\begin{gathered}
\mathrm{H}_{3} \mathrm{C}-\mathrm{CH}\left(\mathrm{CH}_{3}\right)-\mathrm{CH}_{3}+\mathrm{Br} \cdot \rightarrow \\
\mathrm{H}_{3} \mathrm{C}-\mathrm{C} \cdot\left(\mathrm{CH}_{3}\right)-\mathrm{CH}_{3}+\mathrm{HBr}
\end{gathered}
$$

While this reaction is known to produce tertiary halogenated aliphatic compounds by abstracting a second bromine atom from molecular bromine, quenching of this reaction center by oxygen molecules (Reaction R1c) seems to be more likely. Electron-rich tertiary reaction centers like $\alpha$-pinene-induced structures are likely to undergo this abstraction. SOA from catechol or guaiacol are not supposed to exhibit those centers, although aldehydes, derived from ring opening, have weak C-H bonds as well (see also below).

Apart from the reaction of atomic halogens with saturated or unsaturated structural elements, HOX or HX are able to undergo a heterolysis and an addition to unsaturated bonds, where the more electrophilic part is added to the stabilized carbocation. Hypochlorous acid ( $\mathrm{HOCl})$, which is formed during the homogeneous gas-phase reactions and by reaction of molecular chlorine with liquid or surface-adsorbed water, is known to add to unsaturated bonds, forming an alcohol group in $\alpha$-position (Reaction $\mathrm{R} 4)$. $\mathrm{HBr}$ causes the formation of a brominated carbon in $\alpha$ - or terminal position (Reaction R5) according to the rule of Markovnikov (without peroxides) or anti-Markovnikov (in the presence of peroxides, Reaction R1c) (March, 1992).

$\mathrm{R}-\mathrm{CH}=\mathrm{CH}_{2}+\mathrm{HOCl} \rightarrow \mathrm{R}-\mathrm{CHOH}-\mathrm{CH}_{2} \mathrm{Cl}$ 
$\mathrm{R}-\mathrm{CH}=\mathrm{CH}_{2}+\mathrm{HBr} \rightarrow \mathrm{R}-\mathrm{CHBr}-\mathrm{CH}_{3}$

or $\mathrm{R}-\mathrm{CH}_{2}-\mathrm{CH}_{2} \mathrm{Br}$

While no terminal unsaturated bonds are available in the chosen precursors, these reactions can also occur with other unsaturated bonds of the reactive SOA or at aromatic systems. $\alpha$-pinene induced SOA is expected to be rather poor on unsaturated bonds. SOA from catechol and guaiacol still exhibits a large number of unsaturated or aromatic structural elements. Furthermore, these reactions take also place in the quasiliquid phase of the aerosol. The slight increases of the $\overline{\mathrm{OS}_{\mathrm{C}}}$ values in Fig. 8 and of the H/C ratios in Fig. 7 of halogenated species of the processed SOA support the presence of Reactions (4) and (5). On the other hand, a significant contribution of the relative humidity to newly formed species in processed SOA could not be determined. Chlorination of substituted alkanes with $\mathrm{HOCl}$ in $\mathrm{CCl}_{4}$ is reported by Tanner and Nychka (1967). Carpenter et al. (2005) related brominated humic material, sampled in the Hudson Bay, to the reaction with $\mathrm{HOBr}$. Halogenation by $\mathrm{HOCl}$ and $\mathrm{HOBr}$ of aromatic compounds was studied by Voudrias and Reinhard (1988), where the acid catalyzed bromination with $\mathrm{HOBr}$ exhibits significant reaction rates. Vione et al. (2005 and 2008) investigated the halogenation of phenols at simulated atmospheric aerosol conditions in the presence of $\mathrm{H}_{2} \mathrm{O}_{2}, \mathrm{X}^{-}$and $\mathrm{H}^{+}$where HOX is reported as the main halogenating reagent. Aromatic compounds (formed from catechol or guaiacol as precursors), are also expected to undergo electrophilic aromatic substitutions and hence an increase of the degree of substitution. The substituents $\mathrm{OH}-$ and $\mathrm{CH}_{3} \mathrm{O}-$ on benzenes activate the aromatic for the addition of further functional groups according to the Hammett-equation (Zetzsch, 1982). Hence, any substituted aromatic structure on SOA from catechol or guaiacol is available for further substitution reactions by RHS to form aromatic or olefinic C-X bonds, represented by absorptions at lower wavenumbers in the specific spectral region $\left(700-400 \mathrm{~cm}^{-1}\right)$ in Fig. 5. Aliphatic chlorinated compounds exhibit absorptions between 780 and $550 \mathrm{~cm}^{-1}$, while aromatic chlorinated species absorb at $500 \mathrm{~cm}^{-1}$ and below. However, the limitations of the mid-infrared spectral region $\left(4000-400 \mathrm{~cm}^{-1}\right)$ do not allow to measure absorptions of brominated aromatic species $\left(v(\mathrm{C}-\mathrm{Br})_{\text {aromatic }}\right.$ : expected between 400 and $260 \mathrm{~cm}^{-1}$, Socrates, 1980).

While Reactions (1) to (5) modify the carbon structure of the macromolecules of the preformed SOA, other reactions are expected to influence functional groups and hence related aerosol properties like the average carbon oxidation state or vibrational features related to carbonyls or other oxygen containing functional groups. The $\mathrm{NO}_{\mathrm{x}}$-free formed SOA in this study is expected not to contain any different chemical element than carbon, hydrogen and oxygen. Furthermore, in the oxidizing environment of the smog-chamber atmosphere, no chemical reduction will occur. The following part discusses reactions which influence oxygen containing functional groups. However, since there are no metals present in the gas phase or particle phase, reactions which depend on inorganic catalysts like the Hunsdiecker reaction (e.g. March, 1992) are not discussed.

HOX species are also expected to form gaseous halogen containing methanes (like e.g. trihalomethanes) by haloformtype reactions (Carpenter et al., 2005; Mok et al., 2005). In these reactions, a methyl group in $\alpha$-position of a carbonyl containing functional group is substituted by a halogen atom (with HOX as reacting agent) and separated by forming gaseous $\mathrm{CH}_{n} \mathrm{X}_{4-n}$-species. The carbonyl group is simultaneously oxidized to a carboxylic acid. Although the $\alpha$ pinene and guaiacol (and their related aerosols) exhibit reaction centers for haloform-type reactions, no related gaseous halogen-species (rotational coupling of $v(\mathrm{C}-\mathrm{X})$ vibrations) were detected by long-path FTIR spectroscopy between 750 and $600 \mathrm{~cm}^{-1}$ (e.g. Siebert, 1966).

Alcohols are affected by halogen atoms either by hydrogen abstraction in $\alpha$-position (Wu et al., 2003) or by oxidation to aldehydes (Hurley et al., 2004).

The reaction of aldehydes with halogens (Wallington et al., 1989; Ramacher et al., 2000) is dominated by the abstraction of the relatively weakly bonded hydrogen of the aldehyde. A subsequent addition of oxygen (according to Reaction R1c) will cause a one-carbon shorter aldehyde and the release of $\mathrm{CO}_{2}$ (Ramacher et al., 2000). The remaining carbonyl can be separated from the organic molecule (CO release) or be oxidized to a carboxylic acid. A corresponding release of $\mathrm{CO}$ and $\mathrm{CO}_{2}$ was measured for all three types of SOA using longpath absorption FTIR spectroscopy (Fig. 4).

$\mathrm{HOBr}$ (and maybe $\mathrm{HOCl}$ ) is also expected to cause decarboxylation by formation of an acyl hypohalite. Organic acyl hypohalites are discussed e.g. by Anbar and Ginsburg (1954). Pink and Steward (1971) report oxidative decarboxylation caused by bromine water. Formation of acyl hypohalites is also discussed by Shell and May (1983). These reactions explain a possible decarboxylation of the organic aerosols. This is indicated by the decrease of the dominance of the $v(\mathrm{C}=\mathrm{O})$ vibration in Fig. 5 and a strong formation of $\mathrm{CO}_{2}$ (as visible in Fig. 4). Further, a change of the carbonyl vibration is also indicated by long-path absorption FTIR spectroscopy but not shown in Fig. 4 because of a strong interference with gaseous water in the related spectral region.

The formation of gaseous phosgene during the reaction of RHS with SOA can be explained by several basic reaction pathways. Chlorine is able to react with released carbon monoxide (e.g. from the oxidation of aldehydes) similar to Reactions (R2) and (R1b). The decomposition of chloroalkanes and chloroalkenes is reported as the main phosgene source in the troposphere by Helas and Wilson (1992). The temporal resolution of the applied methods of the present study is too low to determine the significant source of phosgene, measured using FTIR spectroscopy in the aerosol smog-chamber. A further processing of haloform-type reaction products to phosgene cannot be excluded. 
The reactions mentioned above can explain several changes observed while processing the preformed organic aerosols from $\alpha$-pinene, catechol and guaiacol with reactive halogen species. However, there is still a lack of literature on heterogeneous gas-phase reactions of halogen species with organic compounds (in the aerosol phase) and how basic organic reaction mechanisms can be applied to atmospheric conditions in the boundary layer.

\subsection{Interaction with RHS from the simulated salt-pan}

In order to obtain more detailed information on possible natural halogenation processes involving organic aerosols, the model aerosols were exposed to natural systems which are known to release gaseous halogen species. The complex data obtained from these systems exhibit strong matrix effects, which hamper the detailed interpretation of the data sets. Thus, the results of the molecular halogen photochemical processing studies were used to identify physicochemical changes related to the organic aerosols.

Results from the interaction of organic aerosols with halogens released from the simulated salt pan are similar to those from experiments with $\mathrm{X}_{2}$ photolysis. A similar increase of the particle diameters is observed. ATR infrared spectra exhibit the same spectral features. The optical properties in the diffuse-reflectance UV/VIS spectral range are comparable to the observed spectra from the molecular experiments and red-shifts as well as blue-shifts are both observed. Although the mass spectra exhibit a poor signal-to-noise ratio, the formation of halogenated compounds (especially chlorinated) seems to be confirmed for the particulate matter.

\subsection{General effects of RHS on SOA and SOA on RHS release-mechanisms}

In general, the investigation of the transformation of physicochemical features of the organic aerosols led to the first steps of an understanding of the complex processes involved. A detailed understanding was not achieved at the present time, as it would require more molecular-based techniques to analyze the processes.

A strong influence of atmospheric halogen species on organic aerosols is indicated by the performed aerosol smogchamber experiments. Several parameters used to characterize the model aerosols are changed by the halogenation process. These changes depend on the particular aerosol as well as on the halogen source. The chemical composition of the organic aerosols determines the details of the changes. Hence, no general "road map" for atmospheric halogenation processes could be identified.

Depending on the kind of SOA and the halogen source, quite different changes in the aerosol size distribution can be observed. The chemical transformation and the related change in optical properties are indicated by the change in the color of the halogenated organic aerosols (haloSOA).
The formation of secondary particles (halogen-induced SOA: XOA) from the reacted SOA could be measured. Furthermore, the main identified gaseous species released from the aerosol are specified.

The reaction of organic aerosols with halogens from natural sources is confirmed by the influence of organic particles on the halogen release-mechanisms themselves. SOA strongly influences the RHS release-mechanism, hampering the bromine explosion and causing a decrease of the ozone depletion.

\section{Conclusions}

Halogens take part in the aging process of organic aerosols. Based on the results of our study, interactions occur in the gas phase as well as in the particle phase. The gas-phase photochemical halogenation generates additional low-volatile compounds, which condense onto the existing particles. Furthermore, the halogenation process releases simple gaseous molecules. The expected decrease in vapor pressure can also lead to new particle formation, caused by the halogenation of the SOA precursor or the oxidized SOA precursor. Therefore, halogens can interact in ways with organic molecules (possible SOA precursors) similar to those suggested in the current literature on nucleation and aging (Kroll et al., 2011).

The entire organic aerosol is processed by the main gaseous halogen species like $\mathrm{X}_{2}, \mathrm{HOX}$, and HX. These species are able to change the chemical structure of the organic backbone by hydrogen abstraction or saturation of unsaturated carbon-carbon bonds. Furthermore, functional groups are affected by the halogens. Abstraction of hydrogen atoms from alcohols or aldehydes and decarboxylation are possible reaction pathways during the degradation of the organic matter of the aerosol. Gas-phase as well as liquidphase halogen chemistry involving atomic and heterolytically split species seems to take place during the reaction of RHS with SOA. However, other methods like time-resolved aerosol flow-reactor spectroscopy are needed to figure out single and important degradation pathways in more detail and clarify the major processes during the complex aerosol halogen interaction.

Those widespread changes of physicochemical properties of SOA, processed by RHS from natural sources, might change the behavior of SOA in the atmosphere. Other important properties of SOA like the ability to act as CCN or IN, the potential to absorb atmospheric organic vapors and water, or the contribution to radiative forcing should be strongly influenced. Therefore, the aerosol-halogen interaction might strongly contribute to the influence of organic aerosols on the climate system.

Acknowledgements. The authors thank the German Science Foundation (DFG) for support within the research unit HALOPROC and the European Union for support within the infrastructure EUROCHAMP 2. Also they wish to thank Heinz-Ulrich Krüger 
(deceased 2012) for continuous technical support of the chamber experiments and Jenny Westphal for the measurement and preprocessing of the ICR-FT/MS analysis. Publication costs were supplied by the German Research Foundation (DFG) and the University of Bayreuth in the funding programme Open Access Publishing.

Edited by: B. Ervens

\section{References}

Anbar, M. and Ginsburg, D.: Organic hypohalites, Chem. Rev., 54, 925-958, 1954.

Atkinson, R., Baulch, D. L., Cox, R. A., Crowley, J. N., Hampson, R. F., Hynes, R. G., Jenkin, M. E., Rossi, M. J., Troe, J., and IUPAC Subcommittee: Evaluated kinetic and photochemical data for atmospheric chemistry: Volume II - gas phase reactions of organic species, Atmos. Chem. Phys., 6, 3625-4055, doi:10.5194/acp-6-3625-2006, 2006.

Baes, A. U. and Bloom, P. R.: Diffuse Reflectance and Transmission Fourier Transform Infrared (DRIFT) spectroscopy of humic and fulvic acids, Soil Sci. Soc. Am. J., 53, 695-700, 1989.

Barrie, L. and Platt, U.: Arctic tropospheric chemistry: An overview, Tellus, 49B, 449-454, 1997.

Bedjanian, Y., Riffault, V., and Poulet, G.: Kinetic study of the reactions of $\mathrm{Br}$ with $\mathrm{HO}_{2}$ and $\mathrm{DO}_{2}$, J. Phys. Chem. A, 105, 573-578, 2001.

Behnke, W. and Zetzsch, C.: Heterogeneous photochemical formation of $\mathrm{Cl}$ atoms from $\mathrm{NaCl}$ aerosol, $\mathrm{NO}_{\mathrm{x}}$ and ozone, J. Aerosol Sci., 21, 229-232, 1990.

Behnke, W. and Zetzsch, C.: Formation of organohalogens from heterogeneous atmospheric chemistry simulated in an aerosol smog chamber, GDCh Monograph, 34, 110-121, 2005.

Behnke, W., Elend, M., Krüger, H.-U., and Zetzsch, C.: The Influence of $\mathrm{NaBr} / \mathrm{NaCl}$ ratio on the bromide-catalysed production of halogenated radicals, J. Atmos. Chem., 34, 87-99, 1999.

Bierbach, A., Barnes, I., and Becker, K. H.: Rate coefficients for the gas-phase reactions of bromine radicals with a series of alkenes, dienes, and aromatic hydrocarbons at $298 \pm 2 \mathrm{~K}$, Int. J. Chem. Kinet., 28, 565-577, 1996.

Boyce, S. D. and Hornig, J. F.: Reaction pathways of trihalomethane formation from the halogenation of dihydroxyaromatic model compounds for humic acid, Environ. Sci. Technol., 17, 202-211, 1983.

Buxmann, J., Balzer, N., Bleicher, S., Platt, U., and Zetzsch, C.: Observations of bromine explosions in smog chamber experiments above a model salt pan, Int. J. Chem. Kinet., 44, 312-326, doi:10.1002/kin.20714, 2012.

Cai, X. and Griffin, R. J.: Secondary aerosol formation from the oxidation of biogenic hydrocarbons by chlorine atoms, J. Geophys. Res., 111, D14206, doi:10.1029/2005JD006857, 2006.

Cai, X., Ziemba, L.D., and Griffin, R. J.: Secondary aerosol formation from the oxidation of toluene by chlorine atoms, Atmos. Environ., 42, 7348-7359, 2008.

Caregnato, P., Gara, P. D., Bosio, G. N., Martire, D. O., and Gonzalez, M. C.: Reactions of $\mathrm{Cl} \cdot / \mathrm{Cl}_{2} \cdot$ - radicals with the nanoparticle silica surface and with humic acids: model reactions for the aqueous phase chemistry of the atmosphere, Photochem. Photobiol., 83, 944-951, 2007.
Carpenter, L. J., Hopkins, J. R., Jones, C. E., Lewis, A. C., Parthipan, R., Wevill, D. J., Poissant, L., Pilote, M., and Constant, P.: Abiotic source of reactive organic halogens in the sub-arctic atmosphere?, Environ. Sci. Technol., 39, 8812-8816, 2005.

Carr, S., Shallcross, D. E., Canosa-Mas, C. E., Wenger, J. C., Sidebottom, H. W., Treacy, J. J., and Wayne, R. P.: A kinetic and mechanistic study of the gas-phase reactions of $\mathrm{OH}$ radicals and $\mathrm{Cl}$ atoms with some halogenated acetones and their atmospheric implications, Phys. Chem. Chem. Phys., 5, 3874-3883, 2003.

Coeur-Tourneur, C., Tomas, A., Guilloteau, A., Henry, F., Ledoux, F., Visez, N., Riffault, V., Wenger, J. C., and Bedjanian, Y.: Aerosol formation yields from the reaction of catechol with ozone, Atmos. Environ., 43, 2360-2365, 2009.

Enami, S., Vecitis, C. D., Cheng, J., Hoffmann, M. R., and Colussi, A. J.: Global inorganic source of atmospheric bromine, J. Phys. Chem. A, 111, 8749-8752, 2007.

Evans, J. C., Lo, G. Y. S., and Chang, Y. L.: The vibrational spectra of acetyl hypochlorite, Spectrochim. Acta, 21, 973-979, 1965.

Fahimi, I. J., Keppler, F., and Schöler, H. F.: Formation of chloroacetic acids from soil, humic acid and phenolic moieties, Chemosphere, 52, 513-420, 2003.

Finlayson-Pitts, B. J.: The tropospheric chemistry of sea salt: A molecular-level view of the chemistry of $\mathrm{NaCl}$ and $\mathrm{NaBr}$, Chem. Rev., 103, 4801-4822, 2003.

Foster, K. L., Plastridge, R. A., Bottenheim, J. W., Shepson, P. B., Finlayson-Pitts, B. J., and Spicer, C. W.: The role of $\mathrm{Br}_{2}$ and $\mathrm{BrCl}$ in surface ozone destruction at polar sunrise, Science, 291, 471-474, 2001.

Frinak, E. K. and Abbatt, J. P. D.: $\mathrm{Br}_{2}$ production from the heterogeneous reaction of gas-phase $\mathrm{OH}$ with aqueous salt solutions: Impacts of acidity, halide concentration, and organic surfactants, J. Phys. Chem. A, 110, 10456-10464, 2006.

Gallard, H. and von Gunten, U.: Chlorination of natural organic matter: kinetics of chlorination and of THM formation, Water Res., 36, 65-74, 2002.

George, I. J. and Abbatt, J. P. D.: Heterogeneous oxidation of atmospheric aerosol particles by gas-phase radicals, Nature Chemistry, 2, 713-722, 2010.

Helas, G. and Wilson, S. R.: On sources and sinks of phosgene in the troposphere, Amos. Environ., 26A, 2975-2982, 1992.

Holzinger, R., Kasper-Giebl, A., Staudinger, M., Schauer, G., and Röckmann, T.: Analysis of the chemical composition of organic aerosol at the Mt. Sonnblick observatory using a novel high mass resolution thermal-desorption proton-transfer-reaction mass-spectrometer (hr-TD-PTR-MS), Atmos. Chem. Phys., 10, 10111-10128, doi:10.5194/acp-10-10111-2010, 2010.

Huang, W.-J., Chen, L.-Y., and Peng, H.-S.: Effect of NOM characteristics on brominated organics formation by ozonation, Environ. Int., 29, 1049-1055, 2004.

Huber, S. G., Kotte, K., Schöler, H. F., and Williams, J.: Natural abiotic formation of trihalomethanes (THM) in soil: Results from laboratory studies and field samples, Environ. Sci. Technol., 43, 4934-4939, 2009.

Hurley, M. D., Wallington, T. J., Sulbaek Andersen, M. P., Ellis, D. A., Martin, J. W., and Mabury, S. A.: Atmospheric chemistry of fluorinated alcohols: Reaction with $\mathrm{Cl}$ atoms and $\mathrm{OH}$ radicals and atmospheric lifetimes, J. Phys. Chem. A, 108, 1973-1979, 2004. 
Iinuma, Y., Böge, O., Gnauk, T., and Herrmann, H.: Aerosolchamber study of the $\alpha$-pinene $/ \mathrm{O}_{3}$ reaction: influence of particle acidity on aerosol yields and products, Atmos. Environ., 38, 761-773, 2004.

Ishikawa, T., Sato, T., Ose, Y., and Nagase, H.: Reaction of chlorine and bromine with humic substance, Sci. Total Environ., 54, 185194, 1986.

Jobson, B. T., Niki, H., Yokouchi, Y., Bottenheim, J., Hopper, F., and Leaitch, R.: Measurements of C2-C6 hydrocarbons during the Polar Sunrise 1992 Experiment: Evidence for $\mathrm{Cl}$ atom and $\mathrm{Br}$ atom chemistry, J. Geophys. Res., 99, 25355-25368, 1994.

Jonsson, A. M., Hallquist, M., and Saathoff, H.: Volatility of secondary organic aerosols from the ozone initiated oxidation of $\alpha$ pinene and limonene, J. Aerosol Sci., 38, 843-852, 2007.

Karlsson, R. S., Szente, J. J., Ball, C., and Maricq, M. M.: Homogeneous aerosol formation by the chlorine atom initiated oxidation of toluene, J. Phys. Chem. A, 105, 82-96, 2001.

Kopetzky, R. and Palm, W.-U.: Formation of halogenated compounds from humic acids in saline solutions, Institut für Ökologie und Umweltchemie - Universität Lüneburg, Lüneburg, 2006.

Kortüm, G. and Oelkrug, D.: Reflexionsspektren fester Stoffe, Naturwissenschaften, 53, 600-609, 1966.

Kroll, J. H., Donahue, N. M., Jimenez, J. L., Kessler, S. H., Canagaratna, M. R., Wilson, K. R., Altieri, K. E., Mazzoleni, L. R., Wozniak, A. S., Bluhm, H., Mysak, E. R., Smith, J. D., Kolb, C. E., and Worsnop, D. R.: Carbon oxidation state as a metric for describing the chemistry of atmospheric organic aerosols, Nature Chemistry, 3, 133-139, 2011.

March, J.: Advanced organic chemistry, John Wiley \& Sons, New York, 1992.

Mellouki, A., Talukdar, R. K., and Howard, C. J.: Kinetics of the reactions of $\mathrm{HBr}$ with $\mathrm{O}_{3}$ and $\mathrm{HO}_{2}$ : The yield of $\mathrm{HBr}$ from $\mathrm{HO}_{2}+\mathrm{BrO}$, J. Geophys. Res., 99, 22949-22954, doi:10.1029/94JD02144, 1994.

Moise, T. and Rudich, Y.: Uptake of $\mathrm{Cl}$ and $\mathrm{Br}$ by organic surfaces - A perspective on organic aerosols processing by tropospheric oxidants, Geophys. Res. Lett., 28, 4083-4086, 2001.

Mok, K. M., Wong, H., and Fan, X. J.: Modeling bromide effects on the speciation of trihalomethanes formation in chlorinated drinking water, Global Nest J., 7, 1-16, 2005.

Mosher, B. W., Winkler, P., and Jaffrezo, J. L.: Seasonal aerosol chemistry at Dye 3, Greenland, Atmos. Environ., 27A, 27612772, 1993.

Nolting, W., Behnke, W., and Zetzsch, C.: A smog chamber for studies of reactions of terpenes and alkanes with ozone and $\mathrm{OH}$, J. Atmos. Chem., 6, 47-59, 1988.

Nordmeyer, T., Wang, W., Ragains, M. L., Finlayson-Pitts, B. J., Spicer, C. W., and Plastridge, R. A.: Unique products of the reaction of isoprene with atomic chlorine: Potential markers of chlorine atom chemistry, Geophys. Res. Lett., 24, 1615-1618, 1997.

Norwood, D. L., Johnson, J. D., Christman, R. F., Hass, J. R., and Bobenrieth, M. J.: Reactions of chlorine with selected aromatic models of aquatic humic material, Environ. Sci. Technol., 14, 187-190, 1980 .

Ofner, J.: Secondary organic aerosol \& atmospheric halogen species, Südwestdeutscher Verlag für Hochschulschriften, Saarbrücken, 2011.
Ofner, J., Krüger, H.-U., Zetzsch, C., and Grothe, H.: Direct deposition of aerosol particles on an ATR crystal for FTIR spectroscopy using an electrostatic precipitator, Aerosol Sci. Technol., 43, 1-5, 2009.

Ofner, J., Krüger, H.-U., and Zetzsch, C.: Time resolved infrared spectroscopy of formation and processing of secondary organic aerosols, Z. Phys. Chem., 224, 1171-1183, 2010.

Ofner, J., Krüger, H.-U., Grothe, H., Schmitt-Kopplin, P., Whitmore, K., and Zetzsch, C.: Physico-chemical characterization of SOA derived from catechol and guaiacol - a model substance for the aromatic fraction of atmospheric HULIS, Atmos. Chem. Phys., 11, 1-15, doi:10.5194/acp-11-1-2011, 2011.

Orlando, J. J., Tyndall, G. S., Apel, E. C., Riemer, D. D., and Paulson, S. E.: Rate coefficients and mechansims of the reaction of $\mathrm{Cl}$-atoms with a series of unsaturated hydrocarbons under atmospheric conditions, Int. J. Chem. Kinet., 35, 334-353, 2003.

Pink, J. M. and Stewart, R.: Mechanism of oxidative decarboxylation of $\alpha$-hydroxy acids by bromine water. Part I. Oxidation in neutral and alkaline medium, Can. J. Chemistry, 49, 649-653, 1971.

Platt, U.: Reactive halogen species in the mid-latitude troposphere - recent discoveries, Water Air Soil Poll., 123, 229-244, 2000.

Platt, U. and Hönninger, G.: The role of halogen species in the troposphere, Chemosphere, 52, 325-338, 2003.

Platt, U. and Janssen, C.: Observation and role of the free radicals $\mathrm{NO}_{3}, \mathrm{ClO}, \mathrm{BrO}$ and $\mathrm{IO}$ in the troposphere, Faraday Discuss., 100, 175-198, 1996.

Platt, U. and Stutz, J.: Differential Optical Absorption Spectroscopy, Springer Verlag, Heidelberg, 2008.

Rahn, K. A., Borys, R. D., Butler, E. L., and Duce, R. A.: Gaseous and particulate halogens in the New York City atmosphere, Ann. NY Acad. Sci., 322, 143-151, 1979.

Ramacher, B., Orlando, J. J., and Tyndall, G. S.: Temperaturedependent rate coefficient measurements for the reaction of bromine atoms with a series of aldehydes, Int. J. Chem. Kinet., 32, 460-465, 2000.

Rontu, N. and Vaida, V.: Vibrational spectroscopy of perfluorocarboxylic acids from the infrared to the visible regions, J. Phys. Chem. B, 112, 276-282, 2008.

Rossi, M. J.: Heterogeneous reactions on salts, Chem. Rev., 103, 4823-4882, 2003.

Rudich, Y.: Laboratory perspectives on the chemical transformations of organic matter in atmospheric particles, Chem. Rev., 103, 5097-5124, 2003.

Saathoff, H., Naumann, K.-H., Möhler, O., Jonsson, Å. M., Hallquist, M., Kiendler-Scharr, A., Mentel, Th. F., Tillmann, R., and Schurath, U.: Temperature dependence of yields of secondary organic aerosols from the ozonolysis of $\alpha$-pinene and limonene, Atmos. Chem. Phys., 9, 1551-1577, doi:10.5194/acp-9-15512009, 2009.

Sax, M., Zenobi, R., Baltensperger, U., and Kalberer, M.: Time resolved infrared spectroscopic analysis of aerosol formed by photo-oxidation of 1,3,5-trimethylbenzene and $\alpha$-pinene, Aerosol Sci. Technol., 39, 822-830, 2005.

Schmitt-Kopplin, Ph., Gelencsér, A., Dabek-Zlotorzynska, E., Kiss, G., Hertkorn, N., Harir, M., Hong Y., and Gebefügi, I.: Analysis of the unresolved organic fraction in atmospheric aerosols with ultrahigh resolution mass spectrometry and nuclear magnetic resonance spectroscopy: Organosulfates as photochemical 
smog constituents, Anal Chem., 82, 8017-8026, 2010.

Schöler, H.-F. and Thiemann, W.: Natural formation of trihalomethanes in the marine and terrestrial environment, GDCh Monograph, 34, 122-131, 2005.

Shell, P. S. and May, D. D.: Ground- and excited-state carboxylate radical chain carriers. Radical chain substitution reactions with acyl hypohalites, J. Am. Chem. Soc., 105, 3999-4008, 1983.

Shevchenko, L. L.: Infrared spectra of salts and complexes of carboxylic acids and some of their derivatives, Russ. Chem. Rev., 32, 201-207, 1963.

Shimanouchi, T.: Tables of molecular vibrational frequencies: Consolidated Volume I, Nat. Stand. Ref. Data Ser., Nat. Bur. Stand. (US), 39, 164 pp., 1972.

Siebert, H.: Anwendungen der Schwingungsspektroskopie in der anorganischen Chemie, Springer Verlag Berlin-Heidelberg-New York, 1966.

Simpson, W. R., von Glasow, R., Riedel, K., Anderson, P., Ariya, P., Bottenheim, J., Burrows, J., Carpenter, L. J., Frieß, U., Goodsite, M. E., Heard, D., Hutterli, M., Jacobi, H.-W., Kaleschke, L., Neff, B., Plane, J., Platt, U., Richter, A., Roscoe, H., Sander, R., Shepson, P., Sodeau, J., Steffen, A., Wagner, T., and Wolff, E.: Halogens and their role in polar boundary-layer ozone depletion, Atmos. Chem. Phys., 7, 4375-4418, doi:10.5194/acp-74375-2007, 2007.

Sjostedt, S. J. and Abbatt, J. P. D.: Release of gas-phase halogens from sodium halide substrates: heterogeneous oxidation of frozen solutions and desiccated salts by hydroxyl radicals, Environ. Res. Lett., 3, 045007, doi:10.1088/1748-9326/3/4/045007, 2008.

Smoydzin, L. and von Glasow, R.: Do organic surface films on sea salt aerosols influence atmospheric chemistry? - a model study, Atmos. Chem. Phys., 7, 5555-5567, doi:10.5194/acp-75555-2007, 2007.

Socrates, G.: Infrared characteristic group frequencies, John Wiley \& Sons, Chichester-New York-Brisbane-Toronto, 1980.

Sörgel, M.: Experimentelle Untersuchung zur Bildung halogenorganischer Verbindungen aus Huminsäuren in Abhängigkeit vom pH-Wert, edited by: Palm, W.-U., Fachbereich Naturwissenschaftliche Technik, Hochschule für Angewandte Wissenschaften, Hamburg, 2007.

Tanner, D. D. and Nychka, N.: Radical chain halogenation reactions of chlorine monoxide, J. Am. Chem. Soc., 89, 121-125, 1967.

Tas, E., Peleg, M., Pedersen, D. U., Matveev, V., Pour Biazar, A., and Luria, M.: Measurement-based modeling of bromine chemistry in the boundary layer: 1 . Bromine chemistry at the Dead Sea, Atmos. Chem. Phys., 6, 5589-5604, doi:10.5194/acp-65589-2006, 2006.

Tretyakova, N. Y., Lebedev, A. T., and Petrosyan, V. S.: Degradative pathways for aqueous chlorination of orcinol, Environ. Sci. Technol., 28, 606-613, 1994.

Uyguner, C. S., Hellriegel, C., Otto, W., and Larive, C. K.: Characterization of humic substances: Implications for trihalomethane formation, Anal. Bioanal. Chem., 378, 1579-1586, 2004.

Vione, D., Maurino, V., Minero, C., Calza, P., and Pelizzetti, E.: Phenol chlorination and photochlorination in the presence of chloride ions in homogeneous aqueous solutions, Environ. Sci. Technol., 39, 5066-5075, 2005.
Vione, D., Maurino, V., Man, S. C., Khanra, S., Arsene, C., Olariu, R.-I., and Minero, C.: Formation of organobrominated compounds in the presence of bromide under simulated atmospheric aerosol conditions, Chemsuschem, 1, 197-204, 2008.

Von Glasow, R. and Crutzen, P. J.: Tropospheric halogen chemistry, Treatise Geochem., 4, 21-64, 2004.

Voudrias, E. A. and Reinhard, M.: Reactivities of hypochlorous and hypobromous acid, chlorine monoxide, hypobromous acidium ion, chlorine, bromine, and bromine chloride in electrophilic aromatic substitution reactions with p-xylene in water, Environ. Sci. Technol., 22, 1049-1056, 1988.

Voudrias, E. A., Larson, R. A., and Snoeyink, V. L.: Effects of activated carbon on the reactions of free chlorine with phenols, Environ. Sci. Technol., 19, 441-449, 1985.

Wagner, T., Ibrahim, O., Sinreich, R., Frieß, U., von Glasow, R., and Platt, U.: Enhanced tropospheric BrO over Antarctic sea ice in mid winter observed by MAX-DOAS on board the research vessel Polarstern, Atmos. Chem. Phys., 7, 3129-3142, doi:10.5194/acp-7-3129-2007, 2007.

Wallington, T. J., Skewes, L. M., Siegl, W. O., and Japar, S. M.: A relative rate study of the reaction of bromine atoms with a variety of organic compounds at $295 \mathrm{~K}$, Int. J. Chem. Kinet., 21, 10691076, 1989.

Wentworth, G. R. and Al-Abadleh, H. A.: DRIFTS studies on the photosensitized transformation of gallic acid by iron(III) chloride as a model for HULIS in atmospheric aerosols, Phys. Chem. Chem. Phys., 13, 6507-6516, 2011.

Wu, H., Mu, Y., Zhang, X., and Jiang, G.: Relative rate constants for the reactions of hydroxyl radicals and chlorine atoms with a series of aliphatic alcohols, Int. J. Chem. Kinet., 35, 81-87, 2003.

Xu, D., Dan, M., Song, Y., Chai, Z., and Zhuang, G.: Concentration characteristics of extractable organohalogens in $\mathrm{PM}_{2.5}$ and $\mathrm{PM}_{10}$ in Beijing, China, Atmos. Environ., 39, 4119-4128, 2005.

Yu, Y., Ezell, M. J., Zelenyuk, A., Imre, D., Alexander, L., Ortega, J., D’Anna, B., Harmon, C. W., Johnson, S. N., and FinlaysonPitts, B. J.: Photooxidation of $\alpha$-pinene at high relative humidity in the presence of increasing concentrations of $\mathrm{NO}_{\mathrm{x}}$, Atmos. Environ., 42, 5044-5060, 2008.

Zetzsch, C.: Predicting the rate of $\mathrm{OH}$-addition to aromatics using $\sigma^{+}$-electrophilic substituent constants for mono- and polysubstituted benzene, XVth Informal Conference on Photochemistry, Stanford, USA, 27 June-1 July 1982.

Zetzsch, C. and Behnke, W.: Heterogeneous photochemical sources of atomic $\mathrm{Cl}$ in the troposphere, Ber. Bunsenges. Phys. Chem., 96, 488-493, 1992.

Zetzsch, C. and Behnke, W.: Heterogeneous reactions of chlorine compounds, NATO ASI Series, I7, 291-306, 1993.

Zetzsch, C., Pfahler, G., and Behnke, W.: Heterogeneous formation of chlorine atoms from $\mathrm{NaCl}$ in a photosmog system, J. Aerosol Sci., 19, 1203-1206, 1988. 